\title{
Characterizing lateral variability of phytoplankton chlorophyll in Chesapeake Bay with aircraft ocean color data
}

\author{
Gregory M. Weiss ${ }^{1, *}$, Lawrence W. Harding $\mathrm{Jr}^{2,3}$, Eric C. Itsweire ${ }^{4}$, \\ Janet W. Campbell ${ }^{1}$ \\ 'Ocean Process Analysis Lab and Earth Sciences Graduate Program, Morse Hall, University of New Hampshire, Durham, \\ New Hampshire 03824, USA \\ ${ }^{3}$ Maryland Sea Grant College, University of Maryland, 0112 Skinner Hall, College Park, Maryland 20742, USA \\ ${ }^{3}$ Horn Point Environmental Laboratory, Center for Environmental and Estuarine Studies, University of Maryland, Box 775 , \\ Cambridge, Maryland 21613, USA \\ ${ }^{4}$ Division of Ocean Sciences, National Science Foundation, Washington, DC 20550, USA
}

\begin{abstract}
The aim of this study was to characterize the small-scale variability (100s of meters to kilometers) of phytoplankton chlorophyll along cross-bay (lateral) flight tracks located in mid-and lower Chesapeake Bay over weekly, seasonal and interannual scales. Analyscis were made on aircraft ocean color data collected in 1990 and 1991 by NASA's Ocean Data Acquisitiun System (ODAS). Lateral varnability was highest durıng the spring bloom events of 1990 and was typically expressed as high westlow east gradients, particularly in the lower bay where up to 6-fold decreases in surface chlorophyll were found along a $15 \mathrm{~km}$ track. There was no spring bloom an 1991, which resulted in low lateral variability throughout the bay. These gradients appear to be assoclated with water masses that differ both physically and chemically along lateral transects. In the lower bay, phytoplankton patch size was within the resolution of future satellite sensors, which will provide even greater temporal coverage of the bay than that provided by aircraft.
\end{abstract}

KEY WORDS: Chlorophyll - Lateral variability · Aircraft remote sensing Chesapeake Bay

\section{INTRODUCTION}

Small-scale patchiness in phytoplankton $(100$ s of meters to kilometers) is ubiquitous in estuarine and coastal waters where physical and biological processes interact on scales of hours to days. These processes, which control the formation and dissipation of phytoplankton patches, are tightly coupled in the nearshore environment, and thus it is difficult to separate and quantify the relative contributions of each process to patchiness (Mackas et al. 1985). The main biological processes responsible for the distribution and abundance of phytoplankton are the differential rates of

\footnotetext{
- Present address: The Harker School, 500 Saratoga Ave, San Jose, California 95129, USA.

E-mail: weiss@kelvin.sr.unh.edu
}

phytoplankton growth and zooplankton grazing. Growth is largely a function of light and nutrients, factors whose horizontal and vertical distributions in estuaries are typically regulated by the seasonal changes in freshwater discharge from the major tributaries (Malone et al. 1988, Harding 1994). However, the influences of these factors on phytoplankton growth are less predictable at smaller scales, because of the effects of a number of physical processes on light and nutrient distributions, including tidal mixing, river fronts, estuarine circulation and bathymetry (Cloern et al. 1983, Malone et al. 1986, Dustan \& Pinckney 1989, Boicourt 1992).

Resolving small-scale heterogeneity in phytoplankton is important because of its significance to population stability and its influences on sampling error (Steele 1974, Haury et al. 1978, Abbot 1993). Small- 
scale variability contributes to sampling error from both ship and aircraft measurements (Wiebe 1971, Harding et al. 1992) and may even affect the accuracy of satellite ocean color measurements (Campbell 1995). Quantifying the scales of patchiness in the nearshore environment is particularly valuable to satellite oceanographers who seek to determine the appropriate sensor resolution and subsequent capabilities for remote-sensing measurements in estuarine and coastal regions. The work in this study is aimed at providing that quantification, based on aircraft remote sensing measurements of chlorophyll in Chesapeake Bay.

In Chesapeake Bay, the largest and most productive estuary in terms of fisheries in the United States, smallscale variability in phytoplankton biomass is expressed along frontal and interfrontal regions (Seliger et al. 1981), in cross-bay (lateral) gradients (Malone et al 1986, Marshall \& Alden 1991, Malone 1992), and in patchy, ephemeral dinoflagellate blooms (Tyler \& Seliger 1978, Tyler 1984). Lateral gradients in chlorophyll, nutrients, and other hydrographic properties are highly variable in the productive mid-bay. Biomass and productivity are typically higher along the western shoal regions, where bathymetry and local circulation patterns provide a retention area for the accumulation of phytoplankton (Seliger et al. 1981, Malone et al. 1986). Periodic lateral seiching of the pycnocline also provides a transport mechanism for the coupling of benthic nutrients regenerated in waters of the deep channel to surface production along the shoals (Malone et al. 1986, Boicourt 1992). Other estuaries, for instance San Francisco Bay, also show relatively higher phytoplankton abundances along the shallow flanks (Cloern et al. 1983)

Sampling small-scale features such as ephemeral blooms and local fronts that produce patchy chlorophyll distributions is difficult using ships. These features are highly dynamic, and low-frequency shipboard sampling often misses either the presence or full extent of these important events. Shipboard sampling precludes a truly synoptic view of small-scale features in the bay; further, the frequency of data collection that is practical and affordable in shipboard studies restricts coverage to relatively small study areas. For this reason, previous studies of phytoplankton patchiness in Chesapeake Bay and elsewhere have been limited in scope and coverage. An alternative approach is to use remotely sensed airborne measurements to augment in situ measurements of chlorophyll. This sampling method allows a study of phytoplankton dynamics on time scales of hours to days, and space scales of 10 s of meters to 100s of kilometers (Campbell \& Esaias 1985, Yoder et al. 1993, Harding et al. 1994), thus providing the synopticity required for a system-wide study of small-scale patchiness. In this study, data from aircraft remote sensing measurements were used to characterize the small-scale phytoplankton dynamics in Chesapeake Bay.

The main goal of this study was to quantitatively characterize the small-scale variability in chlorophyll over a large region of Chesapeake Bay and to compare the findings with chlorophyll patterns found at larger scales. Using a sampling strategy that provides synoptic coverage of bay-wide properties appropriate to address the spatial and temporal scales of variability inherent in estuarine environments, this work builds upon previous studies of small-scale phytoplankton dynamics in Chesapeake Bay. Data from NASA's (National Aeronautics and Space Administration) airborne Ocean Data Acquisition System (ODAS) and several in situ platforms were used to complete the following study objectives: (1) to characterize the variability of chlorophyll along cross-bay (lateral) flight tracks located in the mid-and lower bay over weekly, seasonal and interannual scales, and (2) to elucidate physical and chemical factors that may influence the observed spatial and temporal chlorophyll patterns.

\section{METHODS}

ODAS description and sampling. The ODAS is a passive remote sensing instrument equipped with 3 nadir-viewing radiometers that measure water-leaving radiances in the blue to blue-green regions of the visible spectrum (at wavelengths $\lambda=460,490$, $520 \mathrm{~nm}$, with nominal $15 \mathrm{~nm}$ bandwidths and $2^{\circ}$ fieldsof-view). In addition, the ODAS is equipped with an infrared temperature sensor, the Precision Radiation Thermometer (PRT-5), that measures infrared wavelengths in an 8 to $14 \mu \mathrm{m}$ window to derive sea surface temperature (see Harding et al. 1992).

A spectral curvature algorithm was used to derive surface chlorophyll (chl) from the upwelled radiances (Campbell \& Esaias 1983, Harding et al. 1992, 1995). The algorithm is:

$$
\log \mathrm{chl}=a+b \cdot \log \left(\frac{L_{2}{ }^{2}}{L_{1} \cdot L_{3}}\right)
$$

where $L_{1}, L_{2}$ and $L_{3}$ are water-leaving radiances in the 460,490 and $520 \mathrm{~nm}$ bands, respectively. The coefficients, $a$ and $b$, were empirically derived by regressing ODAS radiances with in situ measurements collected within $\pm 1 \mathrm{~d}$ of the overflight. In situ chl data from the Chesapeake Bay Program (CBP) and Land-Margin Ecosystem Research (LMER) cruises were used to parameterize the algorithm. Estimates of surface chl have an RMS error of 0.2 to $0.3 \log$ units for the regions of the bay that were studied. A detailed discussion of 
the parameterization of the algorithm is presented in Harding et al. (1992, 1995).

Since 1989, the ODAS has been used to measure phytoplankton distribution and abundance in the bay as part of an ongoing monitoring program (Harding et al. 1992). The data presented in this paper were collected on flights in 1990 and 1991. The ODAS and PRT5 instruments were flown on a light aircraft (DeHavilland Beaver) at an altitude of $150 \mathrm{~m}$ at $-50 \mathrm{~m} \mathrm{~s}^{-1}$ over a set of 40 flight tracks (Fig. 1). The 3 visible radiometers and the PRT-5 sample every $0.1 \mathrm{~s}(10 \mathrm{~Hz})$. To reduce instrument noise and sun glint, data were averaged over $5 \mathrm{~s}$ intervals, providing a spatial resolution of $250 \mathrm{~m}$ along a track. The years 1990 and 1991 were particularly interesting due to the strongly contrasting

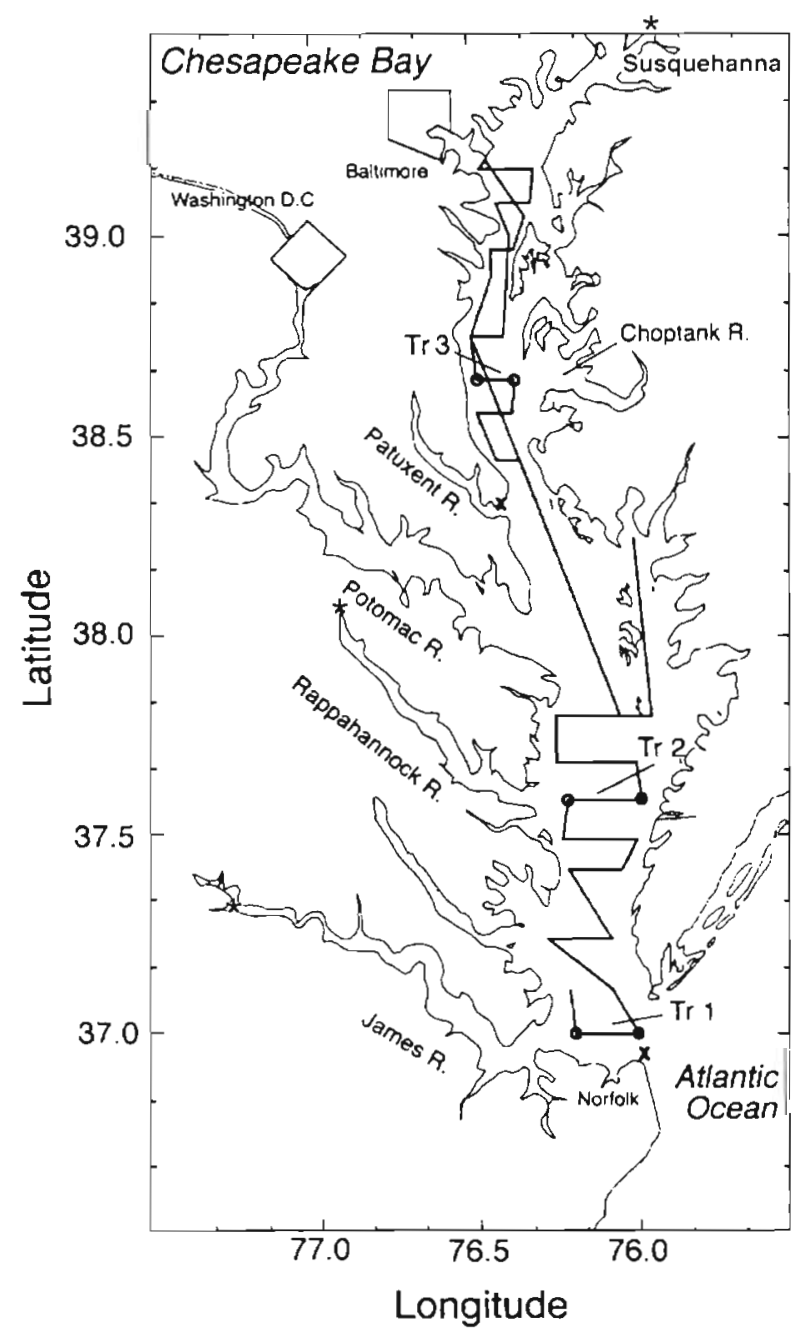

Fig. 1 Chesapeake Bay and the nominal ODAS (Ocean Data Acquisition System) flight tracks. The 3 numbered cross-bay (lateral) tracks ( $\operatorname{Tr} 1, \operatorname{Tr} 2$ and $\operatorname{Tr} 3$ ) were analyzed in this study. In situ data sources were from Chesapeake Bay Program sampling stations in the lower and mid-bay (o), US Geological Survey flow gauges ( $*$ ) and National Oceanic Atmospheric Administration tidal gauges ( $x$ ) annual cycles of bloom formation. In 1990, there was a well-developed spring bloom that occurred over a large region of the bay from early March to late May, followed by several smaller summer blooms in the upper reaches of the bay (Harding et al. 1994, Glibert et al. 1995). In contrast, there was a complete absence of a spring bloom in 1991 and very low concentrations of chlorophyll persisted throughout the spring and summer over the entire bay. The disparity in phytoplankton dynamics between these 2 years has been connected with the interannual differences in Susquehanna River flow rates and their eftects on nutrient loading and light attenuation (Harding et al. 1994). The strong interannual differences of 1990-1991 provide a unique study period in which to relate largerscale variability in phytoplankton to patterns and processes that exist at smaller scales.

Flight tracks. The ODAS flight tracks encompass a large region of the bay (Fig. 1). There were 28 flights in 1990 (March to September), and 31 flights in 1991 (February to September). Three flight tracks normal to the main axis of the bay were selected to represent a large area of the bay (Fig. 1, Table 1). Tracks 1 and 2 are in the lower bay. Track 1 extends $15 \mathrm{~km}$ from the mouth of the James River eastward to the bay entrance and Track 2 begins near the mouth of the Rappahannock River and extends $16 \mathrm{~km}$ eastward. The middle reaches of the bay are represented by Track 3 which is located near the mouth of the Choptank River and is $7 \mathrm{~km}$ long, also with an east-west orientation

In situ measurements. In situ data of chl, temperature (T), salinity (S), dissolved inorganic nitrogen (DIN, computed as the sum of $\mathrm{NO}_{3}{ }^{-}, \mathrm{NO}_{2}{ }^{-}$, and $\mathrm{NH}_{4}{ }^{+}$), and dissolved silicate (DSi) were provided by the CBP. There were 4 sampling stations located near each of the end points of Tracks 1 and 3 (Fig. 1, Table 1). The data from these stations that were closest in time to the airborne coverage were used to identify east to west differences in hydrographic properties that are wellknown forcing factors of phytoplankton distribution and abundance. The differences were calculated as:

$$
\Delta Y=Y_{\text {east }}-Y_{\text {west }}
$$

where $Y$ is the in situ data. Although in situ chl was also collected at these stations, the data were not collected at the same time as the overflights, and thus were not useful for direct comparisons to ODAS chl. Preliminary efforts at comparing the remote and in situ chl measurements were inconclusive because of the presence of high variability over short time scales.

Bathymetry of the 3 tracks (Fig. 2) was determined from sounding data taken from a number of cruises throughout the 1980 s. The relatively deep north-south channel of the bay was located on the eastern bounds of the 2 lower bay tracks while it was near center along 
Table 1 Location of ODAS flight tracks, CBP monttoring stations, flow gauges, and tidal gauges in Chesapeake Bay, giving latitude, longitude and nearest major tributary

\begin{tabular}{|c|c|c|c|}
\hline Track/Stn & Latitude & Longitude & Nearest tributary \\
\hline \multicolumn{4}{|l|}{ ODAS flight tracks } \\
\hline 1 & $36.99^{\circ}-37.00^{\circ} \mathrm{N}$ & $76.19^{\circ}-76.00^{\circ} \mathrm{W}$ & James River \\
\hline 2 & $37.58^{\circ}-37.60^{\circ} \mathrm{N}$ & $76.20^{\circ}-75.99^{\circ} \mathrm{W}$ & Rappahannock River \\
\hline 3 & $38.62^{\circ}-38.66^{\circ} \mathrm{N}$ & $76.48^{\circ}-76.38^{\circ} \mathrm{W}$ & Choptank River \\
\hline \multicolumn{4}{|c|}{ CBP monitoring stations ${ }^{a}$} \\
\hline $\mathrm{S} 2, \mathrm{~S} 4$ & $36.99^{\circ} \mathrm{N}$ & $76.17^{\circ}-76.01^{\circ} \mathrm{W}$ & James River \\
\hline $\mathrm{CB} 4.2 \mathrm{~W}, \mathrm{CB} 4.2 \mathrm{E}$ & $38.64^{\circ} \mathrm{N}$ & $76.50^{\circ}-76.40^{\circ} \mathrm{W}$ & Choptank River \\
\hline \multicolumn{4}{|l|}{ Flow gauges ${ }^{b}$} \\
\hline Cartersville & $37.66^{\circ} \mathrm{N}$ & $78.08^{\circ} \mathrm{W}$ & James River \\
\hline Fredericksburg & $38.32^{\circ} \mathrm{N}$ & $77.52^{\circ} \mathrm{W}$ & Rappahannock River \\
\hline Conowingo & $39.65^{\circ} \mathrm{N}$ & $76.17^{\circ} \mathrm{W}$ & Susquehanna River \\
\hline \multicolumn{4}{|l|}{ Tidal gauges } \\
\hline Bay-Bridge Tunnel & $36.97^{\circ} \mathrm{N}$ & $76.12^{\circ} \mathrm{W}$ & James River \\
\hline Solomons & $38.32^{\circ} \mathrm{N}$ & $76.45^{\circ} \mathrm{W}$ & Patuxent River \\
\hline \multicolumn{4}{|c|}{$\begin{array}{l}\text { Heasly et al. (1989) } \\
\text { webited States Geological Survey, water resources information, world wide } \\
\text { we usgs.gov/public }\end{array}$} \\
\hline
\end{tabular}

13; 7 corresponded to high slack; 2 to 6 corresponded to the flooding tide and 8 to 12 to the ebbing tide stages. With the exception of a potential aliasing found at Track 1 during the first few flights of 1990, which will be discussed later, there was no apparent bias to a given tidal stage for either of the 2 years (Fig. 3 ).

Freshwater discharge data from gauges in the Susquehanna, James and Rappahannock Rivers were obtained from the USGS (United States Geological Survey) (Fig 1, Table 1). The raw data for 1990 and 1991, given as mean daily discharge $\left(\mathrm{m}^{3} \mathrm{~d}^{-1}\right)$, were downloaded from the USGS world wide web page, http://h2o.usgs.gov/public.

Statistical methods. Analyses of the ODAS data sets involved both descriptive statistical methods and timeseries analysis. Four descriptive measures of chl were used to characterize

Track 3. Track 1 was the shallowest of the tracks $(9 \mathrm{~m})$; the western portion of the track was roughly half the depth of the eastern side

Tidal height data were provided by NOAA's (National Oceanic and Atmospheric Administration) Ocean and Lakes Level Division. Data for the 2 study years were collected at stations in the lower and midbay region (Fig. 1, Table 1). Comparisons of tidal stage and flight time for each track on each day were done to assess any potential tidal (low-frequency) aliasing of the ODAS data. Tidal stage was determined from the raw tidal height data using an arbitrary coding scheme ranging from 1 to 13 . Low slack was numbered 1 and

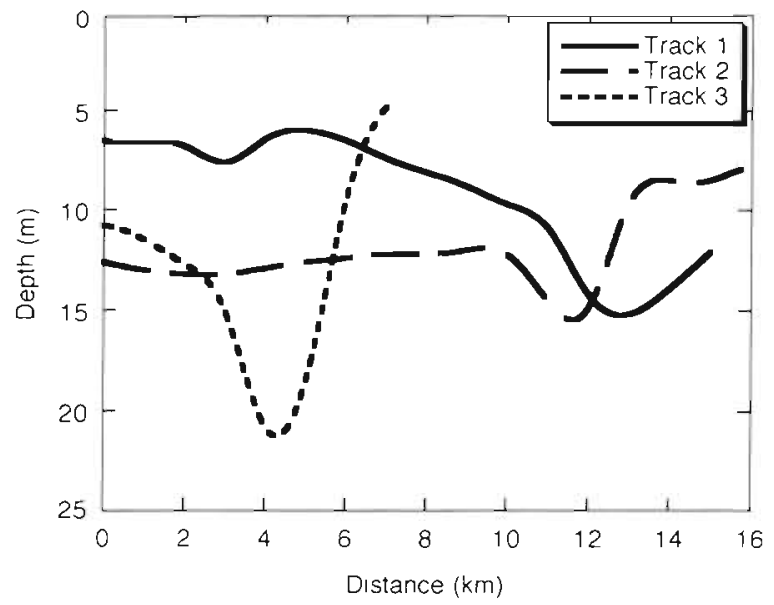

Fig. 2. Bathymetry of the 3 lateral tracks. Note the deep main channel in the center of Track 3 and the eastern position of the channel in the lower bay Tracks 1 and 2 the lateral (west to east) trend in the data, i.e. the large-scale variability along a flight track. Two of the 4 measures computed for each track on each day were the mean chlorophyll (<chl>), expressed as

$$
<\mathrm{chl}>=\frac{1}{\mathrm{n}} \sum_{i=1}^{\mathrm{n}} \mathrm{chl}_{i}
$$

and the coefficient of variation $(\mathrm{CV})$ :

$$
\mathrm{CV}=\frac{\mathrm{SD}}{\mathrm{chl}}
$$

where SD is the standard deviation. The other measures were the linear slope $(m)$ and the coefficient of determination $\left(\mathrm{r}^{2}\right)$ which were determined from linear regressions (ordinary least square) of chl against track distance; these were used to measure the direction and magnitude of lateral gradients with distance measured from west to east. A negative slope corresponded to a decrease, or negative gradient, in chl from west to east. Initially, significance levels were computed for both $m$ and $r^{2}$. However, it was found that statistical significance occurred with no apparent trend. This can be attributed to the fact that samples along the track were not independent, thus producing an inflated level of significance (i.e. overestimated degrees of freedom). Alternatively, the $\mathrm{r}^{2}$ was found to be a good indicator, albeit descriptive, of linear structure for along-track chl distribution. After reviewing the entire set of regressions, it was found that $r^{2}=0.25$ was a suitable threshold for separating well-organized, linear gradients from unstructured, random distributions. Regressions with $r^{2}>0.25$ were used in the quantification of linear trends 
(a)

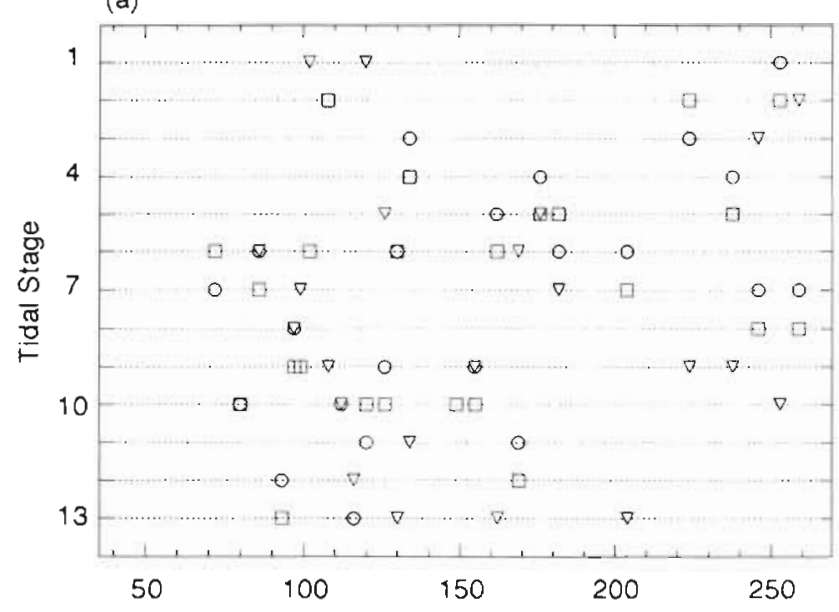

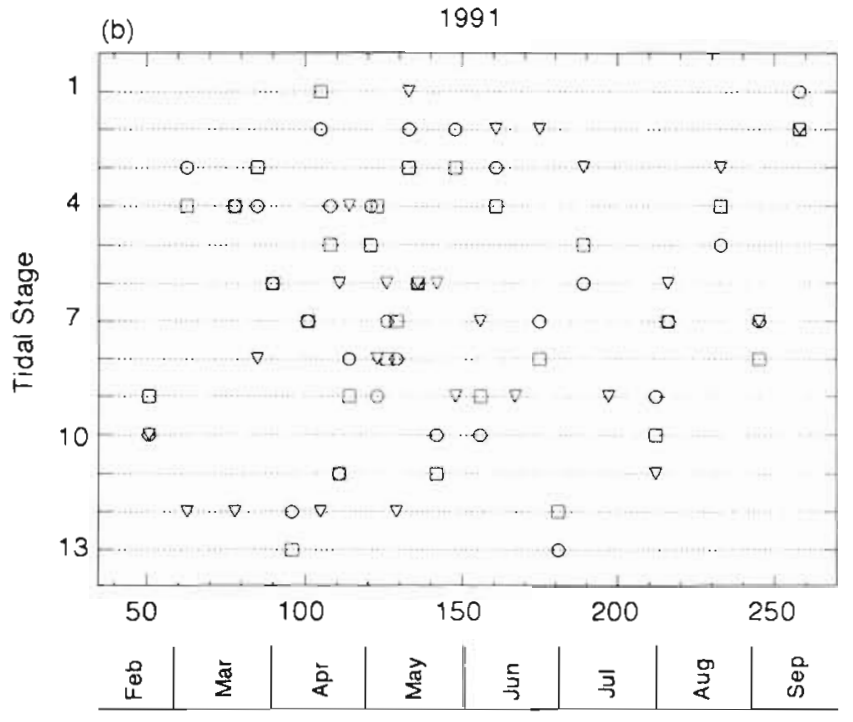

Day of Year
Fig. 3. Tidal stage and the corresponding flight time at each of the 3 tracks for (a) 1990 and (b) 1991

This first-order model was used to describe and quantify the occurrence of lateral trends in ODAS chl along the selected flight tracks. Regressions were also computed for PRT-5 temperature data against track distance and against ODAS chl to assess the influence of lateral water mass structure (i.e. estuarine circulation) on the lateral distribution of chl. The results were used solely to describe trends; no cause-and-effect relationships were inferred from the regression results.

Smaller-scale variability was quantified by using 2 statistical descriptors applied to the residuals (i.e. the detrended data). The descriptors were the relative standard error (SE) and correlation length, which is derived from the autocorrelation function (ACF). The SE was defined as:

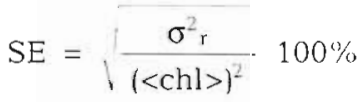

where $\sigma_{r}^{2}$ is the variance of the residuals, and $\langle\mathrm{chl}\rangle$ is the mean of the original track series (Powell et al. 1986). The correlation length provides a quantitative measure of the small-scale patchiness that is superimposed on the larger-scale trend. An ACF was computed for each track on each day to derive a correlation length of surface chl. The ACF is the variance-normalized autocovariance function, which is expressed as:

$$
\mathrm{ACF}=\frac{C(x)}{\sigma_{r}^{2}}
$$

where $\sigma_{r}^{2}$ is the variance of the residual series and $C(x)$ is the autocovariance function which is calculated as:

$$
C(x)=\frac{1}{N} \sum_{N-x}^{n=1} u_{n} u_{n \leq x}
$$

where $x$ is lag number, $u_{\mathrm{n}}$ is chl and $u_{n+x}$ is chl at a distance $\pm x$ and $N$ is the number of data points. Spatial lag $(\Delta x)$ was $250 \mathrm{~m}$ with a maximum lag of $5000 \mathrm{~m}$ $(\approx 33 \%$ of the series) for the lower bay tracks and $2500 \mathrm{~m}$ for Track 3

The correlation length is defined as the maximum distance over which 2 values of chl are correlated and was identified operationally as the first zero-crossing of the ACF (Campbell \& Esaias 1985, van Es 1993). The correlation length can also be identified as the distance at which the ACF is not significantly different from zero at a $5 \%$ significance level. However, it has been a common practice to define patch size as the first zerocrossing; thus, to faciliate comparison of our results with those of past studies, this method was also used in this study.

Cross-correlations were computed on the residuals of the chl and PRT-5 data series to quantify the smallscale patterns of ODAS chl and temperature covariance. The cross-correlation was calculated using the formula:

$$
\operatorname{CCF}(x)=\frac{1}{N} \sum_{N-x}^{n=1} u_{n} v_{n \pm x}
$$

where $x$ is lag number, $u_{n}$ is chl and $v_{\mathrm{n} \pm x}$ is temperature at a distance $\pm x$. Spatial lag was the same as described for the ACF and maximum lag $\left(\Delta x_{\max }\right)$ was 2000 and $1000 \mathrm{~m}$ for the lower and mid-bay tracks, respectively. 
The $\Delta x_{\max }$ was decreased to increase the statistical certainty and to constrain the covariance analysis to near zero lags (W. Brown pers. comm.).

Flow and tides. Daily river discharge at varying time lags were plotted against the large-scale chl descriptors, CV and $r^{2}$, and the small-scale descriptors, SE and correlation length, to determine if temporal variations in flow influenced lateral trends and smaller-scale variability in chl. A 7 d mean flow was also computed for the river flow data and was plotted against the 4 descriptors. The $7 \mathrm{~d}$ mean represented the 7 days prior to a given flight day. In addition, tidal stage was plotted against the 4 descriptors to assess the influence of the tidal cycle, i.e. tidal mixing and frontogenesis, on the distribution of chl along the tracks.

\section{RESULTS}

\section{Annual/interannual variability in $<\mathrm{chl}\rangle$}

There were strongly contrasting annual cycles of phytoplankton abundance and variability along the 3 flight tracks in 1990 and 1991 (Figs. 4 \& 5). The predominant features of the 1990 time series were the spring bloom and the high lateral variability of chl associated with this event, as indicated by the $\pm 1 \mathrm{SD}$ vertical bars in Fig. 4. Surface chl increased during early to mid-April in a large part of the estuary, and these high concentrations persisted until mid-May (Fig. 4). <Chl> was highest in the mid-bay, which had 2 maxima, one in early April and then one in late May (Fig. 4). Maximum <chl> ranged from $21 \mathrm{mg} \mathrm{m}^{-3}$ (Track 1) to $43 \mathrm{mg} \mathrm{m}^{-3}$ (Track 3). During the summer months, <chl> was roughly half of the spring means for all tracks.

In contrast to 1990, there was no evidence of a spring bloom in 1991 (Fig. 5). Low <chl> and low variability persisted throughout spring and summer. Values of $<$ chl> ranged from 5 to $15 \mathrm{mg} \mathrm{m}^{-3}$ from February through September. A seasonal difference in <chl> was evident only along Track 2 (Table 2).

\section{Lateral variability}

In general, the magnitude of lateral variability was related to the magnitude of $\langle\mathrm{chl}\rangle$, as shown in Fig. 6 . In particular, when <chl> was high, lateral variability was also high. For example, the 3 tracks sampled on May 7 in 1990 and 1991 illustrate this common finding in the difference between bloom and non-bloom periods (Fig. 7). The cross-bay distribution of chl in 1991 was relatively featureless as contrasted with strong directional gradients (up to 6-fold) in 1990. The
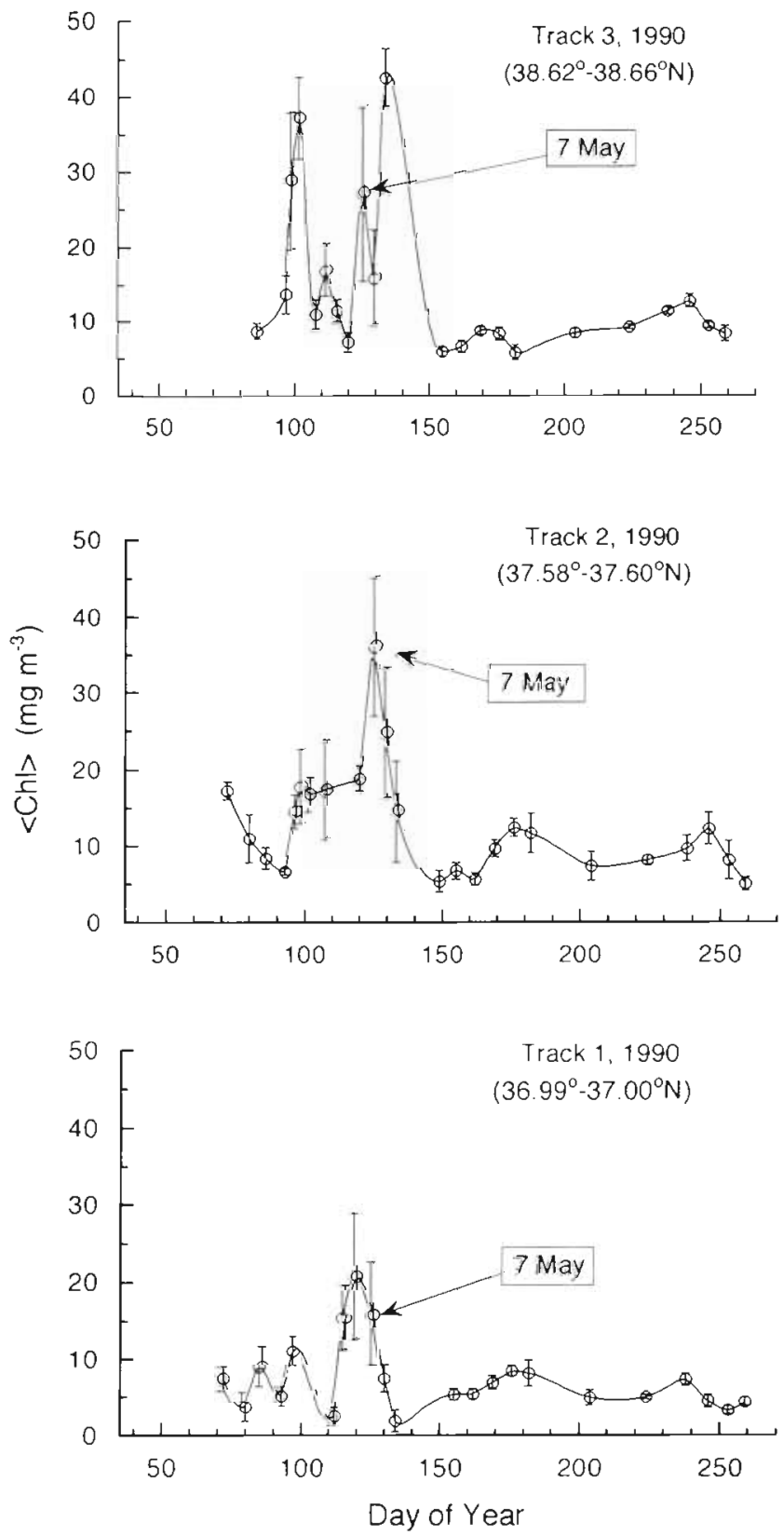

Fig. 4. Annual cycle (Mar-Sep) of mean surface chl for the 3 flight tracks in 1990 . Vertical bars are \pm 1 SD, and represent the cross-bay variability along flight tracks. The lateral distribution of chl along the 3 flight tracks for May 7, 1990 (highlighted by the arrow), is shown in Fig. 7

absence of lateral variability on May 7, 1991, corresponds to the low chl observed in spring of that year, while the gradient in 1990 accompanied high chl values near the peak of the spring bloom (see Figs. 4 \& 5). Lateral variability during the summer of 1990 was about $40 \%$ of the spring average for Tracks 1 and 3 (see CVs, Table 2). In contrast, Tracks 1 and 2 during 1991 showed roughly twice as much variability in the summer in comparison to the spring (Table 2). 

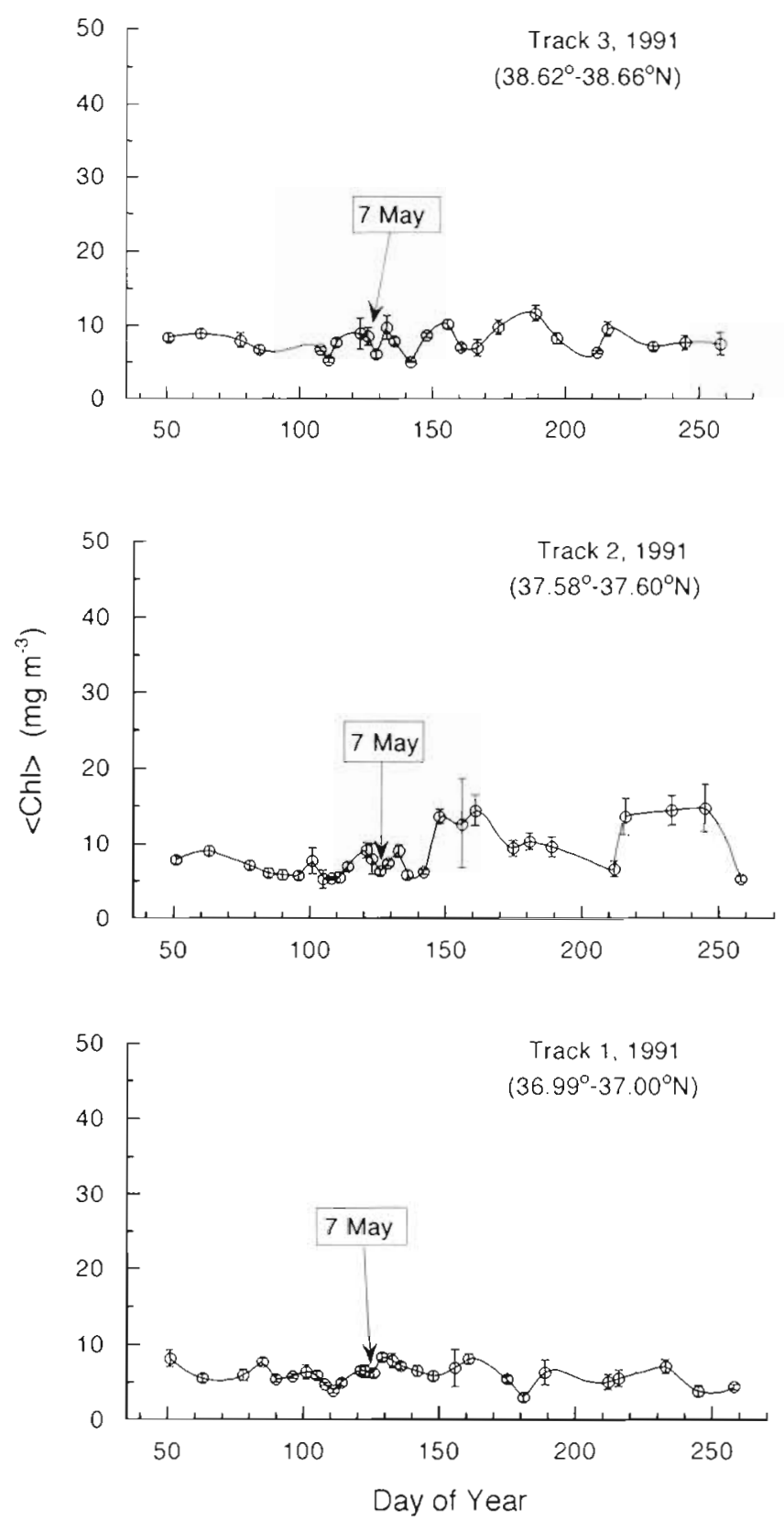

Fig. 5. Annual cycle (Feb-Sep) of mean surface chl for the 3 flight tracks in 1991 Vertical bars are \pm 1 SD. The lateral distribution of chl along the 3 flight tracks for May 7, 1991 (highlighted by arrow), is shown in in Fig. 7

Variability on shorter temporal scales (i.e. days) was common along all tracks. It was particularly pronounced along Track 1, where strong lateral gradients persisted throughout the spring months (1990) with several episodic (scale of days) changes to a more random distribution, and then a subsequent return to a more organized gradient. For example, during spring 1990, a recurring negative gradient in chl distribution was evident, particularly during the peak bloom
Table 2. Seasonal and annual average descriptors of ODAS chl along the 3 flight tracks for spring (Mar-May. Feb-May for 1991), summer (Jun-Sep) and annual (Mar-Sep), in (a) 1990 and (b) 1991 Descriptors for the larger-scale trends are the mean $(<\mathrm{ch}]>)$, coefficient of variation $(\mathrm{CV})$, coefficient of determination $\left(\mathrm{r}^{2}\right)$ and slope $(m)$. Smaller-scale (i.e. residuals) descriptors are the standard error (SE, as \% of <chl>) and correlation length $(C L)$

\begin{tabular}{|c|c|c|c|c|c|c|}
\hline Track & $\begin{array}{c}<\mathrm{Chl}> \\
\left(\mathrm{mg} \mathrm{m}^{-3}\right)\end{array}$ & $\begin{array}{l}\text { CV } \\
(\%)\end{array}$ & $r^{2}$ & $\left.\underset{\left(m g ~ c h l ~ m^{-3}\right.}{m} \mathrm{~km}^{-1}\right)$ & $\begin{array}{c}\text { SE } \\
(\%)\end{array}$ & $\begin{array}{r}\mathrm{CL} \\
(\mathrm{km})\end{array}$ \\
\hline \multicolumn{7}{|l|}{ (a) 1990} \\
\hline 1 Spring & 9.2 & 35 & 0.60 & 0.61 & 20 & 1.9 \\
\hline Summer & 5.9 & 14 & 0.48 & 0.16 & 9 & 1.7 \\
\hline Annual & 7.5 & 24 & 0.54 & 0.40 & 14 & 1.8 \\
\hline 2 Spring & 16.2 & 22 & 0.33 & 0.54 & 17 & 1.4 \\
\hline Summer & 8.8 & 17 & 0.31 & 0.27 & 13 & 1.4 \\
\hline Annual & 12.8 & 20 & 0.32 & 0.45 & 15 & 1.4 \\
\hline 3 Spring & 20.1 & 22 & 0.28 & 2.38 & 17 & 0.7 \\
\hline Summer & 8.6 & 9 & 0.14 & 0.26 & 8 & 0.4 \\
\hline Annual & 14.4 & 15 & 0.21 & 1.68 & 13 & 0.6 \\
\hline \multicolumn{7}{|l|}{ (b) 1991} \\
\hline 1 Spring & 6.3 & 9 & 0.42 & 0.10 & 7 & 1.4 \\
\hline Summer & 5.5 & 18 & 0.43 & 0.21 & 12 & 1.1 \\
\hline Annual & 5.9 & 12 & 0.42 & 0.14 & 9 & 1.3 \\
\hline 2 Spring & 7.2 & 11 & 0.30 & 0.11 & 9 & 1.8 \\
\hline Summer & 11.1 & 17 & 0.24 & 0.25 & 14 & 1.7 \\
\hline Annual & 8.6 & 13 & 0.28 & 0.14 & 11 & 1.8 \\
\hline \multirow{3}{*}{$\begin{array}{l}3 \text { Spring } \\
\text { Summer } \\
\text { Annual }\end{array}$} & 7.4 & 9 & 0.29 & 0.33 & 9 & 0.7 \\
\hline & 8.3 & 10 & 0.41 & 0.28 & 7 & 1.0 \\
\hline & 7.8 & 10 & 0.35 & 0.30 & 8 & 0.9 \\
\hline
\end{tabular}

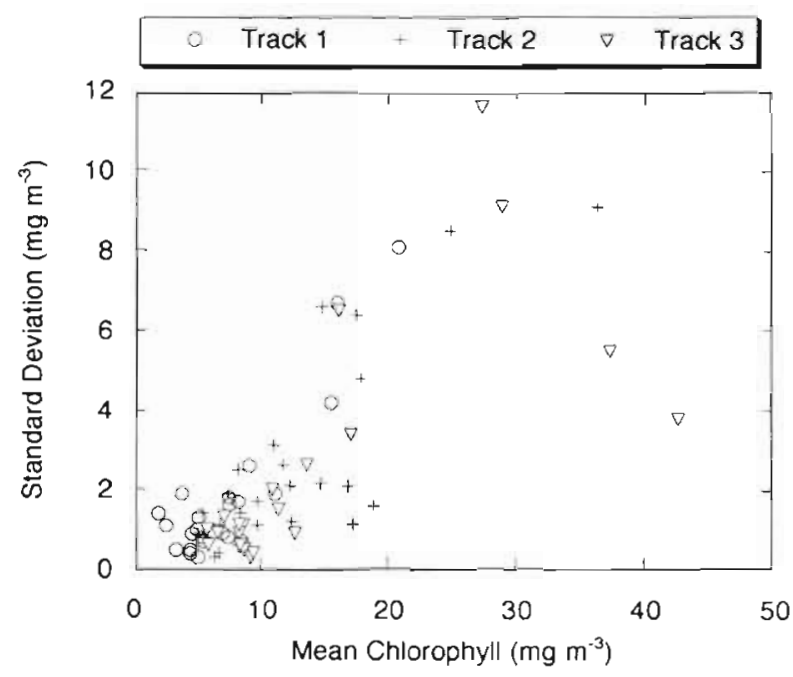

Fig. 6. Relationship between mean chl and standard deviation for 3 tracks in 1990

period. However, during the decline of the bloom, the well-organized gradient changed to a more random distribution within a matter of days (Fig. 8a-c). Reorganization back to the negative gradient occurred within several days (Fig. 8d), although the gradient 

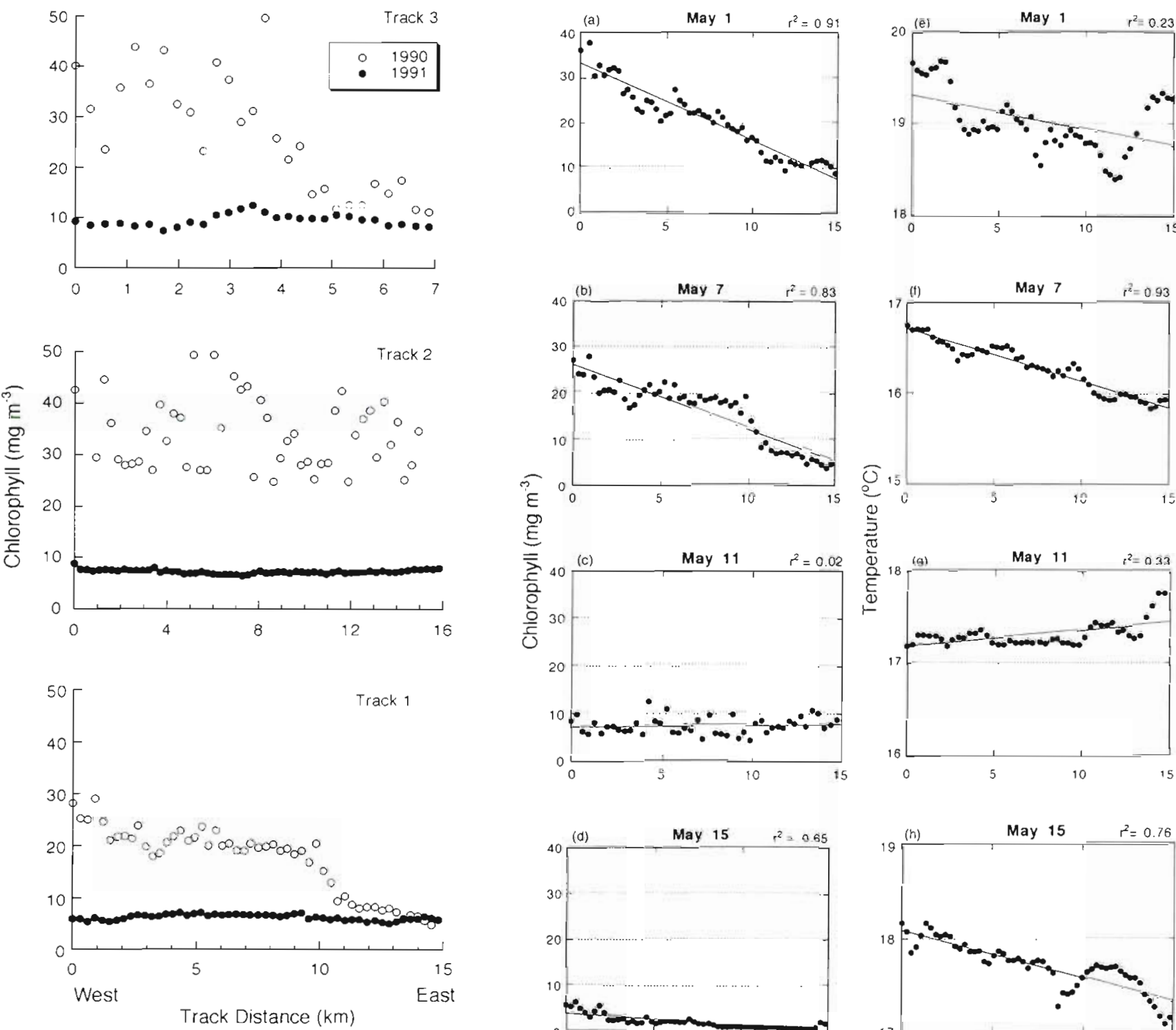

Fig. 7 Lateral distribution of chl for bloom (1990) and non-bloom (1991) periods, along the 3 flight tracks for May 7
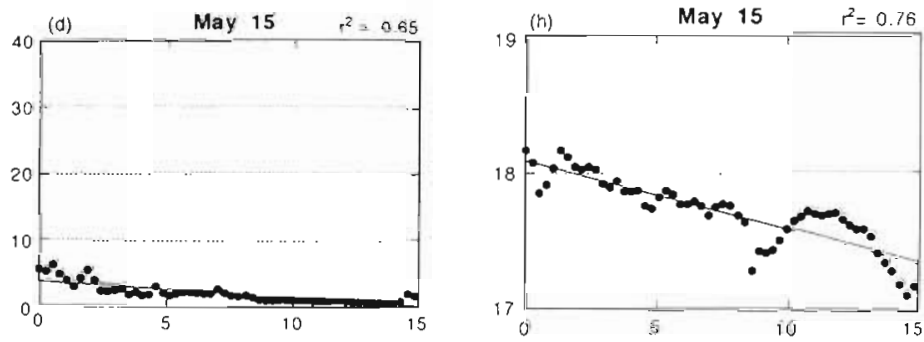

Fig. 8. Short-term changes in the distribution of $(a-d) c h l$ and $(e-h)$ temperature along Track 1 during May 1990. ChI and temperature were measured concurrently with the ODAS

was greatly reduced. Changes in the lateral distribution of surface temperature closely coincided with the chl changes (Fig. 8e-h), a phenomenon which was particularly common along Track 1. Intraseasonal changes were also evident in 1991, although the magnitude and persistence of gradients were much lower.

\section{Linear trends}

A linear model was used to characterize the direction and magnitude of lateral trends along the 3 flight tracks. We found that regressions with $r^{2}>0.25$ had an observable west to east trend; whereas with $r^{2}<0.25$ there was no obvious lateral structure. Track 1 showed the most structure with $71 \%$ of the days (both years combined) having $\mathrm{r}^{2}>0.25$. Along Tracks 2 and 3 , observable west to east trends were present on $53 \%$ and $40 \%$ of the days, respectively.

The common pattern of a west to east decrease resulted in a high frequency of negative slopes (Fig. 9). A negative slope was found for $77 \%$ of the flights in 1990 and $86 \%$ in 1991. However, the mean slope in

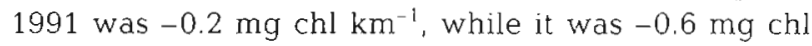



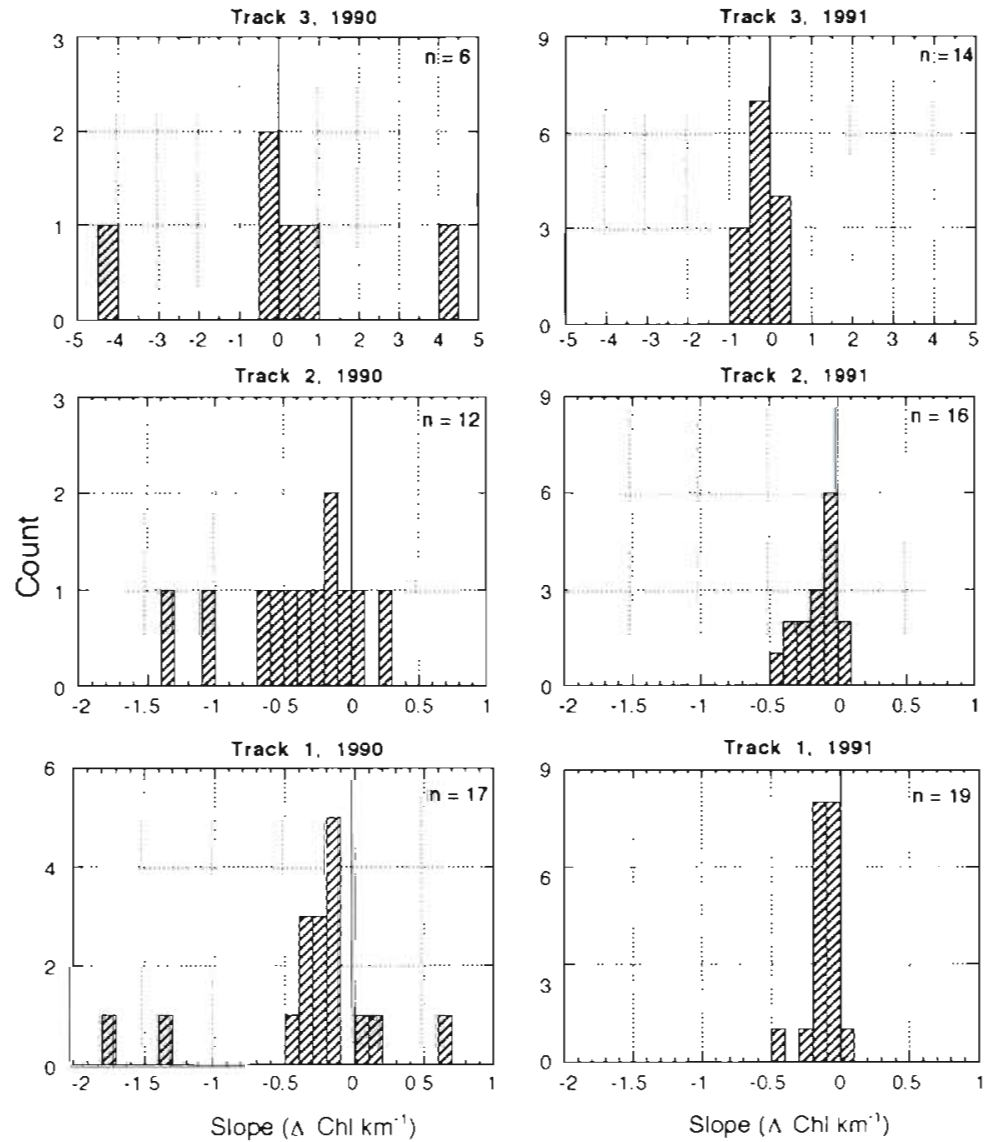

Fig. 9. Histograms of well-structured negative gradients (i.e. negative slopes, $r^{2}>0.25$ ) derived from regressions of chl against track distance for the 3 flight tracks in both 1990 and 1991 The linear slope was used as a descriptor for the direction and magnitude of lateral chl gradients

$\mathrm{km}^{-1}$ for 1990 . Strong negative gradients were prevalent during the spring bloom of 1990 but were rare during the summer (Table 2). Weaker, well-structured gradients were fairly common in summer 1991. The lower bay tracks showed a more consistent pattern of negative gradients (Fig. 9). Directional gradients in the mid-bay were less consistent, particularly in 1990 (Fig. 9), although, during the spring bloom of 1990 , strong negative and positive gradients occurred in the upper bay (Fig. 9).

\section{Variability about the trend}

The relative standard error ( $\mathrm{SE}$ ) of the residuals was computed for each track on each day. Results are presented as seasonal and annual averages in Table 2. Small-scale variability was highest along Tracks 1, 2 and 3 during spring 1990, with average SE values roughly 2 times greater than the summer 1990 averages for Tracks 1 and 3 , and 3 and 2 times greater than
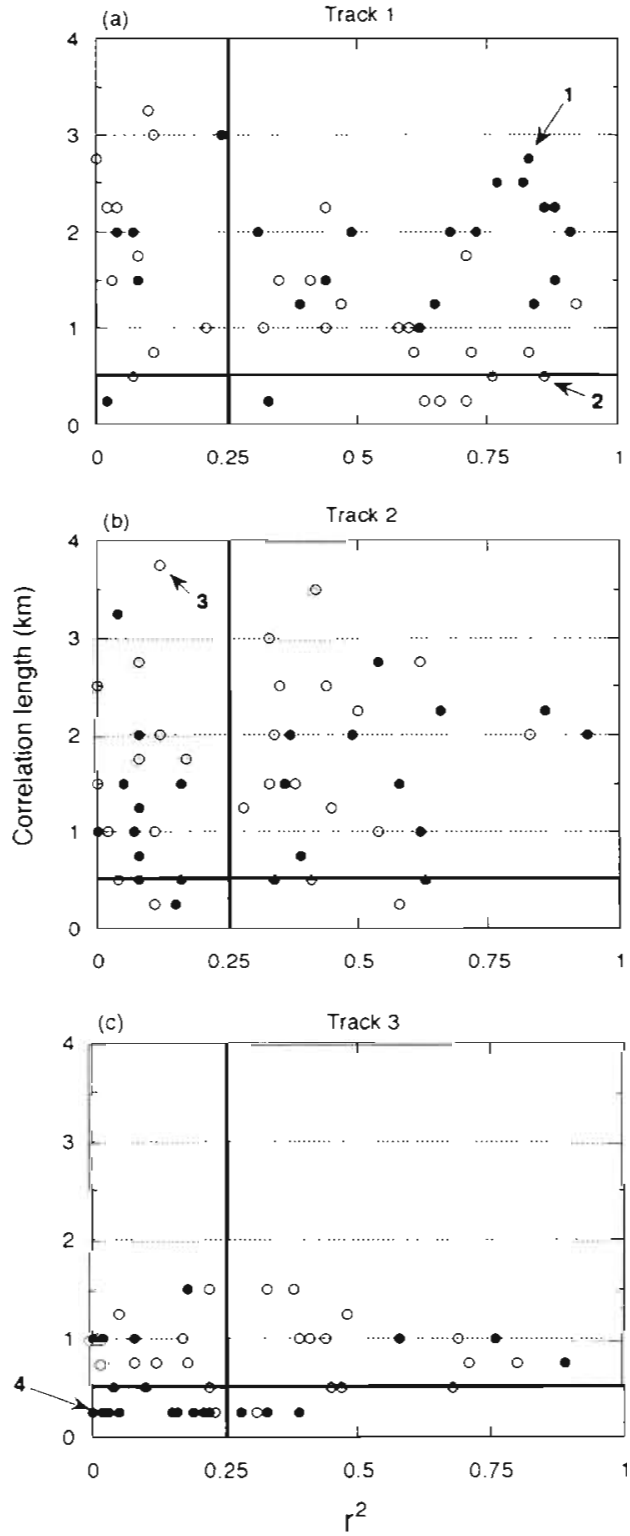

Fig. 10. Linear structure (as described by $\mathrm{r}^{2}$ ) of the lateral distribution of chl for each track on each day compared to the corresponding correlation length. Data from ( 1990 and (O) 1991. The vertical line at $r=0.25$ represents the cutoff for well-organized lateral trends; the horizontal line at a correlation length of $0.5 \mathrm{~km} \mathrm{rep-}$ resents the cutoff for structure in the residuals. The arrows highlight the 4 days which represent the extremes of the 4 types of spatial patterns (see Table 3 for details)

in spring 1991, respectively. The opposite was true for Track 1 in 1991, where the summer SE was roughly 2 times that of spring 1991 (Table 2).

Correlation lengths of ODAS chl varied greatly along both tracks. Values ranged from 0.25 to $3.75 \mathrm{~km}$ in the lower bay and from 0.25 to $1.50 \mathrm{~km}$ along the mid-bay track. The correlation lengths for Tracks 1 and 
Table 3. The 4 types of spatial pattern defined based on the relationship between degree of lateral structure $\left(r^{2}\right)$ and the correlation length (CL). Examples of each are examined in more detail in Fig. 11a-d

\begin{tabular}{|c|c|c|c|c|}
\hline Type & Description & $C L(k m)$ & $r^{2}$ & Example \\
\hline 1 & $\begin{array}{l}\text { Structured, } \\
\text { with trend }\end{array}$ & $>0.5$ & $\geq 0.25$ & Fig. $11 \mathrm{a}$ \\
\hline 2 & $\begin{array}{l}\text { Unstructured, } \\
\text { with trend }\end{array}$ & $\leq 0.5$ & $\geq 0.25$ & Fig. $11 \mathrm{~b}$ \\
\hline 3 & $\begin{array}{l}\text { Structured, } \\
\text { without trend }\end{array}$ & $>0.5$ & $<0.25$ & Fig. 11c \\
\hline 4 & $\begin{array}{l}\text { Unstructured, } \\
\text { without trend }\end{array}$ & $\leq 0.5$ & $<0.25$ & Fig. 11d \\
\hline
\end{tabular}

2 in 1990 were similar, with annual averages of 1.8 and 1.4, respectively (Table 2). Annual averages for the 2 tracks in 1991 were also similar. Track 3, during the summer months, showed a 2 -fold increase between 1990 and 1991 (Table 2) and had typically smaller correlation lengths ( 0.6 to $0.9 \mathrm{~km}$ ) than in the lower bay. In general, the correlation length was highly independent of the degree of organization in the lateral trend of chl, as indexed by the $\mathrm{r}^{2}$ values (Fig. 10).
Four types of spatial pattern were used to define the lateral structure of chl, based on $r^{2}$ and its correlation length. The 4 types are described in Table 3 , and examples of the extremes of each type (as indicated on Fig. 10) were examined in more detail. The chl distributions, residuals and correlograms of these 4 extremes are shown in Fig. 11a-d. These examples reveal that for distributions with a well-organized trend $\left(r^{2}>0.25\right)$ the correlation length quantitatively describes the spatial patchiness around the linear fit (Fig. 11a, b). Further, distributions with no linear trend $\left(r^{2}<0.25\right)$ may still exhibit smaller-scale structure (Fig. 11c), resulting in a relatively large correlation length. In contrast, chl mays exhibit a completely random distribution, as shown along Track 3 during summer 1990 (Fig. 11d), which resulted in small patch sizes of $0.25 \mathrm{~km}$.

\section{Temperature and chlorophyll patterns}

Lateral trends in temperature (PRT-5) were often closely associated with chl (e.g. Fig. 8). Negative gradients were also common in temperature distributions, particularly along Track 1 in the late spring and sum-
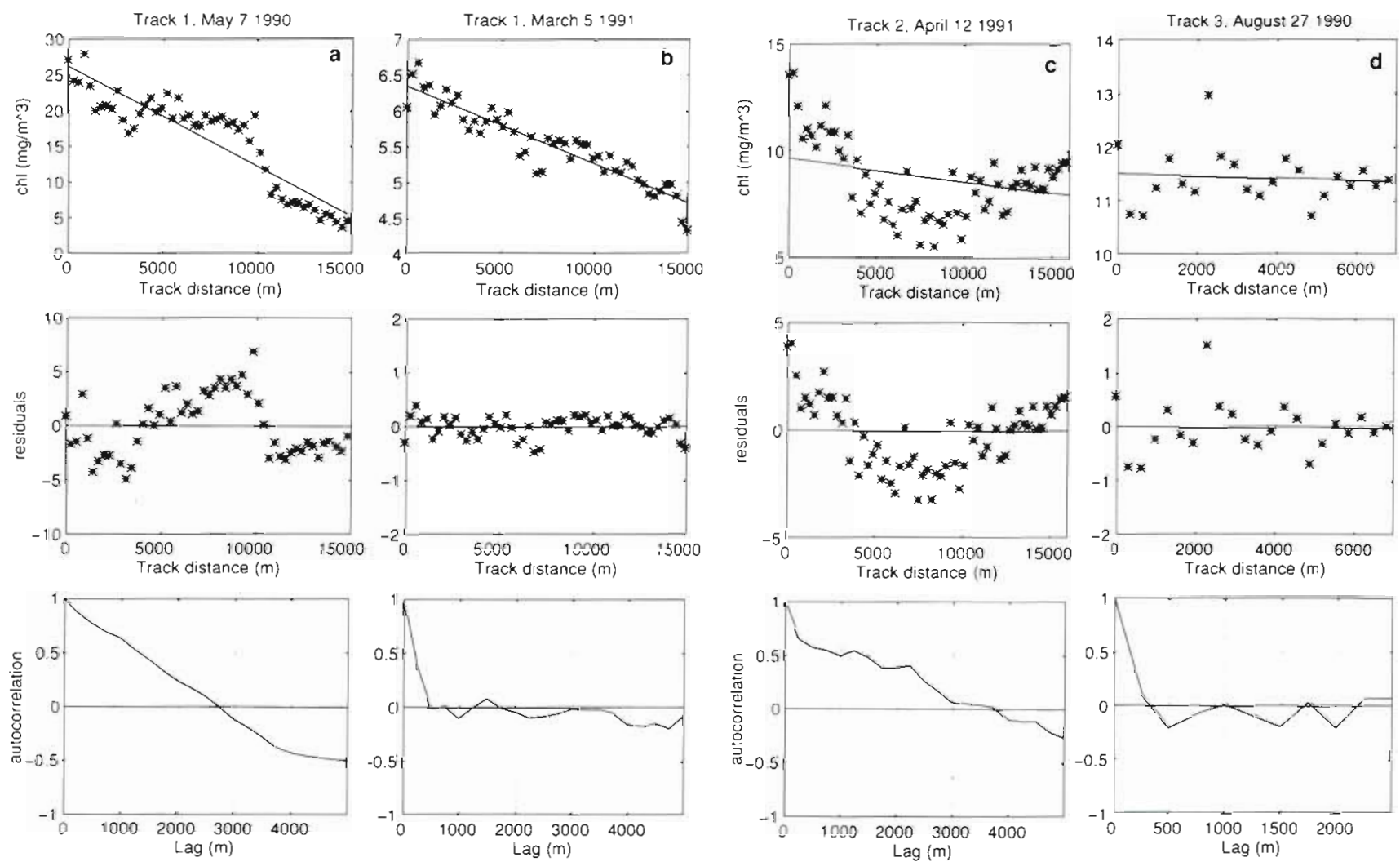

Fig. 11. Lateral distribution of chl, residuals after linear detrending, and correlogram for the first 4 days highlighted in Fig. 10: (a) Track 1, May 7, 1990; (b) Track 1, Mar 5, 1991; (c) Track 2, Apr 12, 1991; (d) Track 3, Aug 27, 1990. The correlation length was determined as the first zero-crossing of the autocorrelation function 
mer months. Track 2 exhibited less structure and consistency, whereas Track 3 had considerable lateral structure, although the high westlow east pattern was less consistent. It was found that when chl and temperature were spatially correlated, the lateral gradient of chl was often strong, particularly during the summer season along Track 1 and the spring for Track 3 (Fig. 12). Although no direct causal relationship between temperature and chl are inferred, these results suggest that lateral water mass differences may influence the trends commonly found in the chl data.

Cross-correlations of chl and temperature residuals were computed on the 4 examples highlighted in Fig. 11 to examine smaller-scale interactions between the 2 variables (Fig. 13). Maximum correlation was found at or near zero lag. The 2 examples with large chl patch sizes (i.e. Fig. 11a, c) showed a significant $(p>0.05)$ positive correlation up to a $500 \mathrm{~m}$ lag (Fig 13a, c), whereas the other, unstructured examples (i.e short correlation lengths) were only significant at the zero lag (Fig. $13 b, d)$.

\section{In situ data}

In situ measurements corroborate the trend in lateral variations observed in the ODAS data. Large west to east differences of chl, S, and T were commonly observed (Fig. 14a, b). In situ chl was higher at the western station (negative $\Delta s$ ) for greater than $75 \%$ of the total days sampled. At Track 1 (Fig. 14a), S was always higher on the eastern side of the bay (positive $\Delta s$ ), with cross-bay $S$ ranges of 2 to 7 psu. At Track 3 (Fig. 14b), S on the eastern flank was equal to or higher than $\mathrm{S}$ on the western flank throughout both years, although differences were relatively smaller than at Track 1 . West to east differences in $T$ greater than $1.0^{\circ} \mathrm{C}$ were also observed, although the directionality was less consistent. The lateral patterns of $\mathrm{S}$ and $\mathrm{T}$ are consistent with the large-scale circulation patterns found in the bay. That is, colder, saltier ocean water enters along the eastern side of the bay, whereas warmer, fresher water from the upper bay moves seaward along the western side.
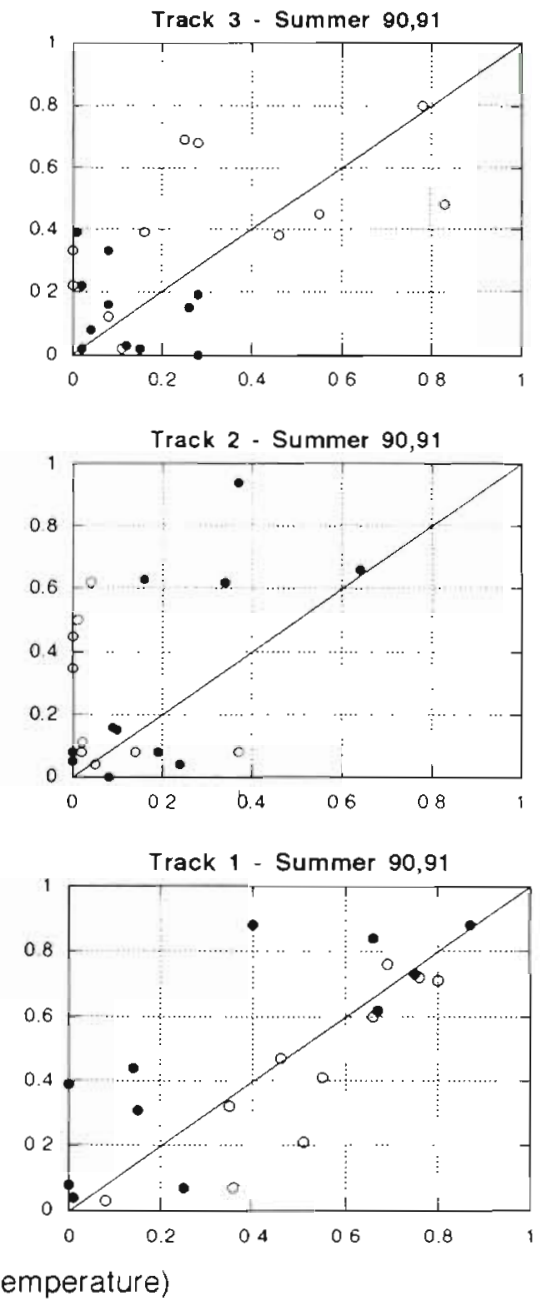

$r^{2}$ (Chl vs. temperature)

Fig. 12. Relationship between the correlation of determination $\left(\mathrm{r}^{2}\right)$ of chl versus T-5 temperature regressions and chl versus track distance regressions. These comparisons showed that when chl and temperature were correlated, the corresponding lateral structure of chl was high. Solid line shows a one-to-one relationship

Concentrations of dissolved nutrients, DIN and DSi, also showed strong lateral differences. DIN was higher at the western station along Track 1 during all of spring and summer in 1990, but was less consistent in 1991 (Fig. 14a). There were several days with particularly high differences along Track 3 (Fig. 14b), although the location of highest values was not uniformly on the western side of the bay. DSi was typically higher on the western side of the bay, and large differences between stations were particularly evident along Track 1 for both 1990 and 1991 (Fig. 14a).

\section{Tides and river flow}

The tidal cycle had little effect on the distribution of chl along all the 3 tracks. The 4 descriptors of lateral trend and 2 descriptors of residual-scale variability 

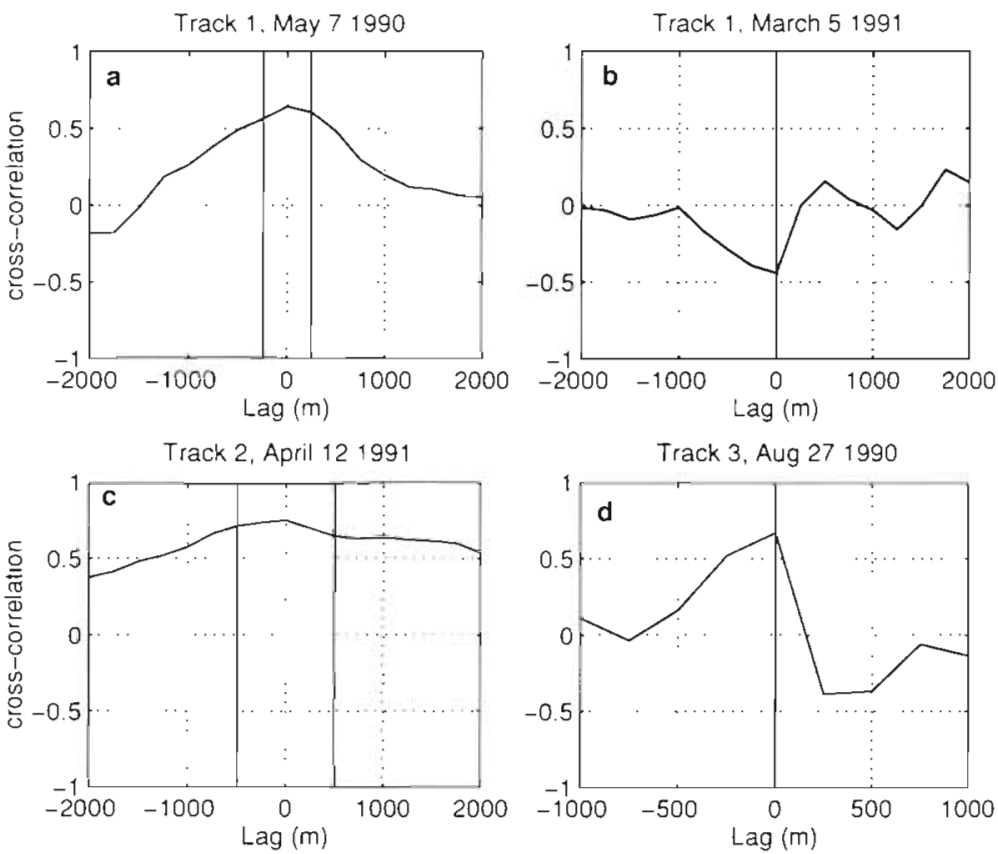

Fig. 13. Cross-correlations of residual $\mathrm{chl}$ and temperature for the 4 examples shown in Fig. 11 The vertical bars indicate at which lags the correlations were significant $(\alpha=0.05)$ were compared to tidal stage. There was no indication of a correspondence between tide stage and any of the descriptors of cross-bay chl along any of the tracks (eg. Track 1; Fig. 15).

Similar results were found with river flow. The annual cycle (1990 and 1991) of freshwater flow is shown for the 3 rivers with the corresponding cycles of <chl> superimposed in Fig. 16. Although there is an apparent agreement between river flow and <chl> at Track 3 in 1990 (Fig. 16), there was no correlation between the 2 variables for 1,7 and $30 \mathrm{~d}$ lags. In addition, there was no relationship found between the descriptors and $7 \mathrm{~d}$ mean flow at any track, as illustrated for Track 1 in Fig 17. Additionally, there was no relationship with temporal lags in flow of 1 to $7 \mathrm{~d}$ for the lower bay tracks and with 1 to $7 \mathrm{~d}$ and 1 mo lags for Track 3, 1991. The results found in Fig. 17 are a good representation of the findings for the other tracks.

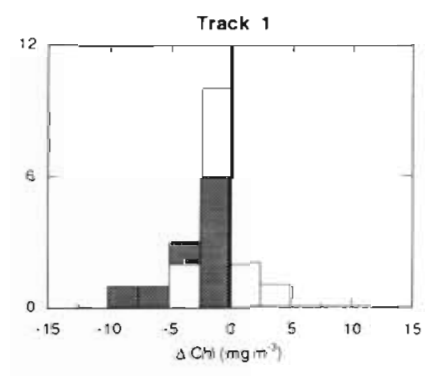

a

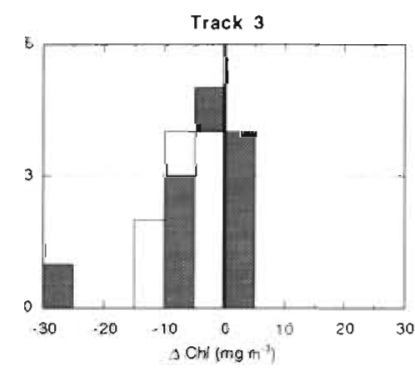

b
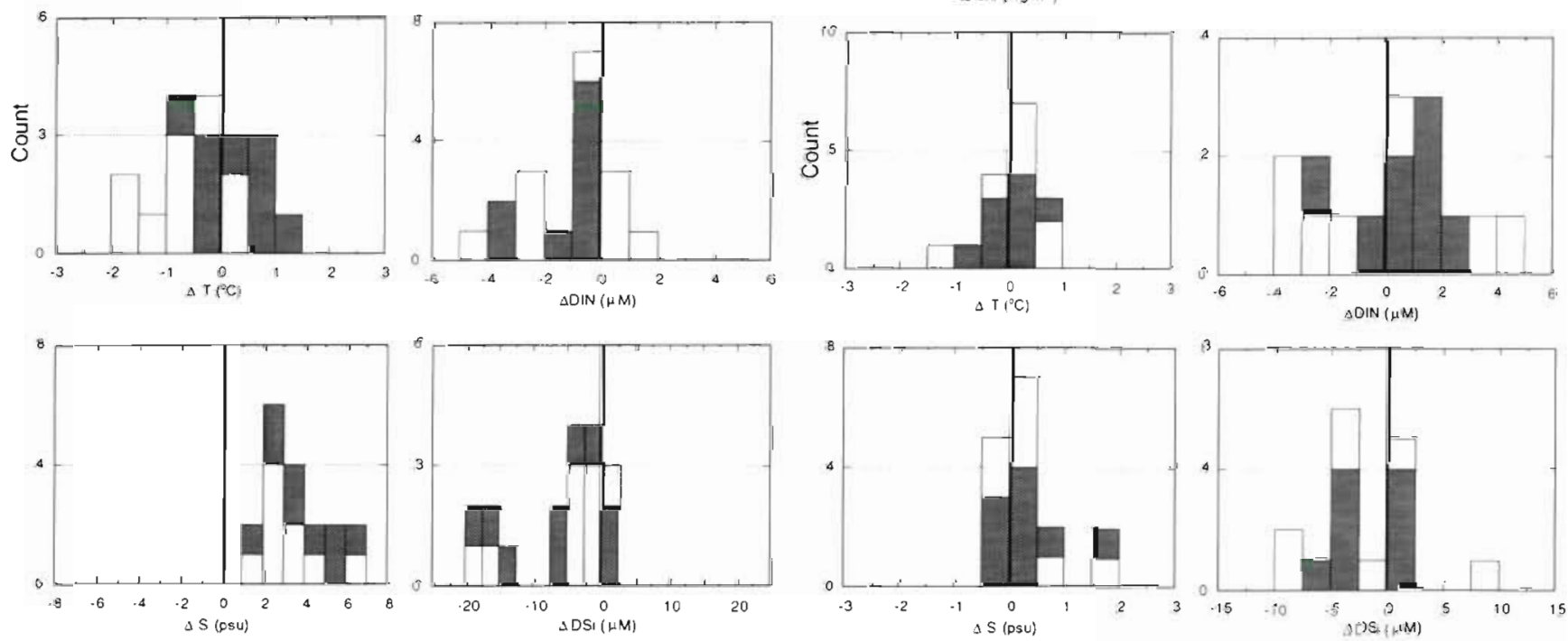

Fig. 14. Frequency histograms of in situ data: chl, temperature, salinity, dissolved inorganic nitrogen (DIN), and dissolved silicate (DSi), expressed as station differences $\left(\Delta Y=Y_{\text {east }}-Y_{\text {west }}\right)$ for stations located at the end points of (a) Track 1 and (b) Track 3 
Fig. 15. Large-scale descriptors, (a) CV and (b) $r^{2}$, and small-scale des. criptors, (c) SE and (d) correlation length, of surface chl compared to the stage of tide at which the flight was conducted along Track 1 in 1990 and 1991. See Fig. 3 for tidal stage code legend
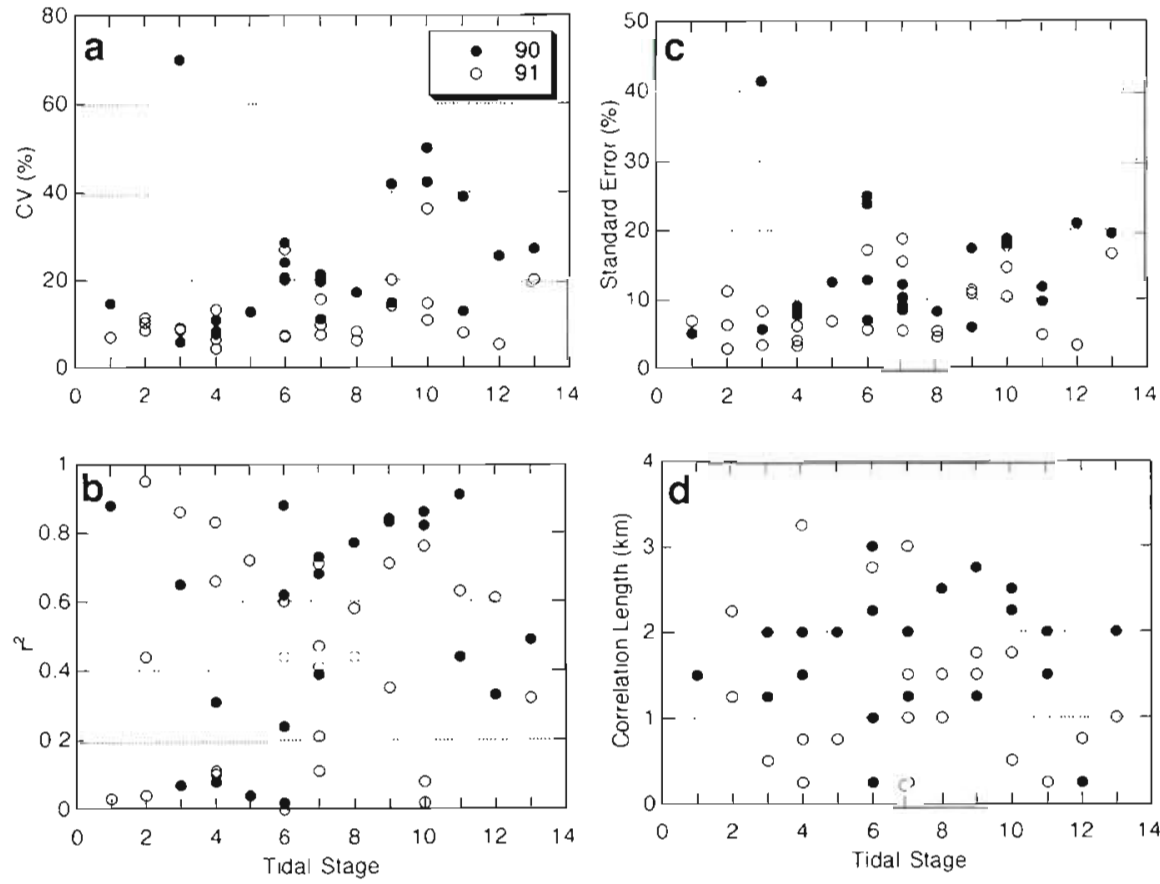
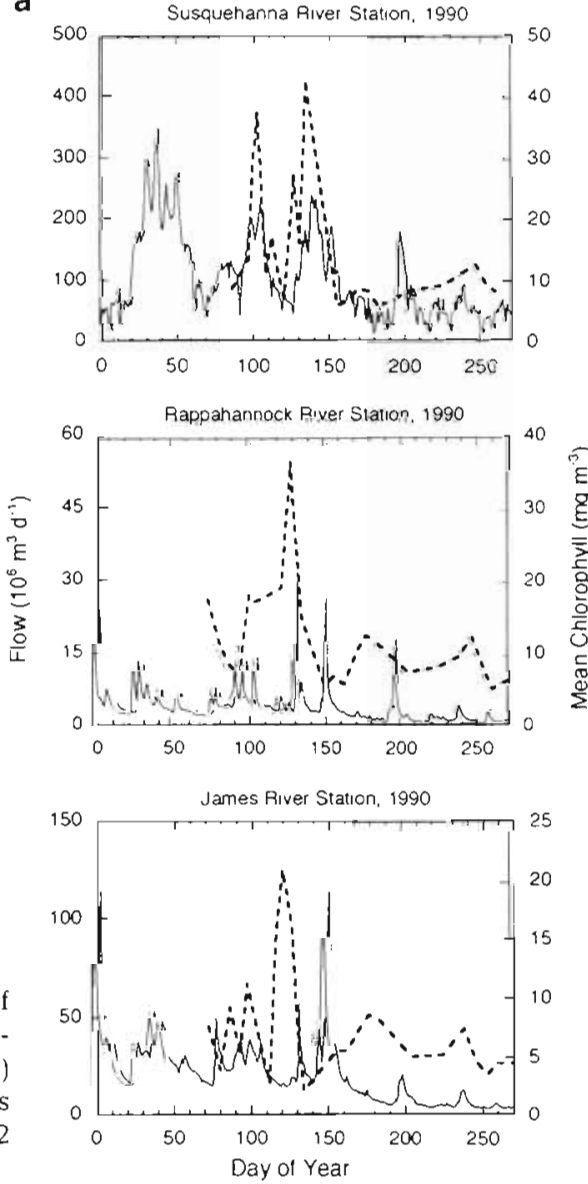

b
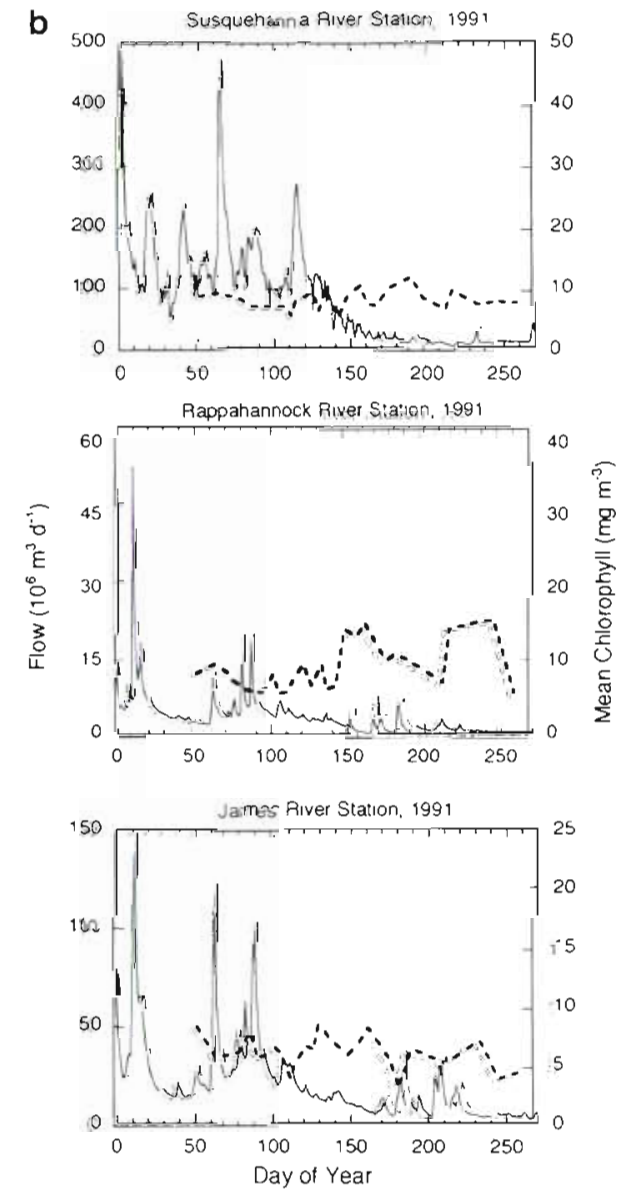

Fig. 16. Daily mean flow (-) of the Susquehanna, Rappahannock and James Rivers for (a) 1990 and (b) 1991. Annual cycles (--) of mean chl for Tracks 3,2 and 1 , respectively 

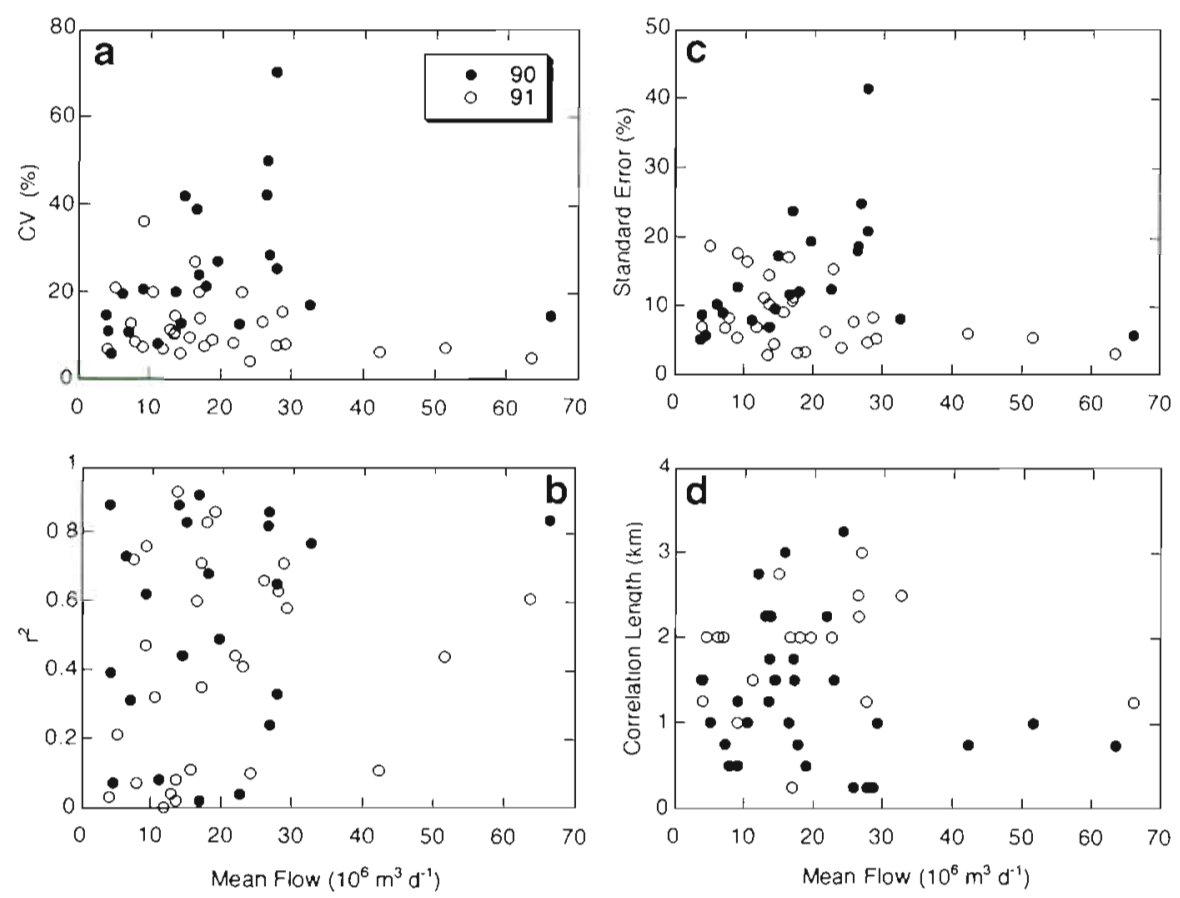

Fig. 17. Large-scale descriptors, (a) CV and (b) $\mathrm{r}^{2}$, and small-scale descriptors, (c) SE and (d) correlation length, of surface chl compared to a $7 \mathrm{~d}$ mean flow of the James River. There was also no relationship found at lag flow of 1 to $7 \mathrm{~d}$

\section{DISCUSSION}

Surface chl derived from airborne remote sensing was used to characterize lateral variations of phytoplankton abundance in Chesapeake Bay. The distribution of chl along 7 to $16 \mathrm{~km}$ flight tracks normal to the mainstem axis of the bay was highly variable, particularly during seasonal blooms when chl exceeded $15 \mathrm{mg}$ $\mathrm{m}^{-3}$. The high variability was often in the form of a strong gradient, most often expressed as a high westlow east distribution. These negative gradients occurred in both spring and summer, although the strongest gradients were found during the spring bloom of 1990. Large gradients were particularly common in the spring months in the lower bay. In the midbay track, the magnitude and direction of lateral gradients were less predictable.

Differences in lateral trends and smaller-scale variability between 1990 and 1991 appeared to be associated with large-scale, system-wide patterns of chl. There was uniformly lower chl in 1991 than in 1990 , and the associated lateral variability was also lower in 1991. The comparison of chl distributions for 7 May in 1990 and 1991, depicting a strong west to east gradient in 1990 and the absence of a gradient in 1991, illustrates this common finding (Fig. 7). Results show that high variability coincides with peak chl, as in spring 1990, and that lateral variability is suppressed when chl is low.

Although variability about the trends (as measured by the SE) along Track 1 was higher in 1990 than in
1991, no interannual differences were found in patch size, as measured by correlation length. The average patch size in the lower bay was approximately 2 times longer than in the mid-Bay, where patch sizes were comparable to those found in a low-variability region in San Francisco Bay (Powell et al. 1986). Differences in patch size between lower and mid-bay tracks were more likely a function of the bay width and bottom topography, since no local environmental factors (i.e. tides and river outflow) were found to influence patch size, although residual temperature and chl were found to be correlated during several flights. Patch sizes of 1 to $2 \mathrm{~km}$, found in the lower bay, are near but within the resolution of future ocean color satellites (e.g. Seaviewing Wide Field-of-view Sensor, SeaWiFS), which should allow the application of satellite chl measurements to assess changes in chl abundance in the bay at a much greater frequency (every 1 to $5 \mathrm{~d}$ depending on cloud cover) than is afforded by aircraft coverage.

Lateral trends in ODAS chl were consistent with gradients found in the in situ chl, S, T, DIN and DSi measurements. Gradients of S, T and nutrients help explain the patterns of surface chl observed in airborne sampling as they show that water masses on western and eastern sides of the bay differ both physically and chemically. For example, along Track 1 near the bay's mouth, a consistent west to east increase of S occurred, which reflects the predominant influence of estuarine circulation and freshwater inputs from the large, western tributaries on the lateral distribution of salt (Pritchard 1952, Itsweire \& Phillips 1987, Boicourt 
1992). Nutrient concentrations also showed strong lateral gradients in this region of the bay. These gradients are commonly associated with the inflow of relatively nutrient-deplete shelf waters along the eastern side of the bay, local inputs of nutrients by large tributaries entering the western side of the bay, and spatial gradients of uptake driven by differences in phytoplankton abundance (Boicourt 1992, Marshall 1995). Along Track 3 in the mid-bay, west to east gradients of $S$ and $\mathrm{T}$ were less common than in the lower bay where the effects of estuarine circulation on the lateral distribution of hydrographic properties are more consistent and pronounced. However, several large cross-bay gradients in DIN and DSi (up to $10 \mu \mathrm{M}$ ) over the $7 \mathrm{~km}$ track were observed, a difference that is highly significant relative to north-south differences over much longer transect lengths (Fisher et al. 1988, 1992, Conley \& Malone 1992). Previous studies have found that high lateral variability in the mid-bay region was often driven by the periodic reversing of the lateral tilt in the pycnocline associated with strong southern winds (Tyler 1984, Malone et al. 1986, Sanford et al. 1990 , Boicourt 1992, Malone 1992). In Chesapeake Bay, the pycnocline is tilted upward to the east. Reversals in the tilt induce upwelling of nutrient-rich bottom waters to the shallow western flank and thus promote phytoplankton growth.

Negative gradients of chl occurred more frequently in the lower bay. This may be due to bathymetric differences between tracks. Track 1 was much shallower along the western side; west-east differences in bathymetry along the other tracks were less pronounced. Shoal regions are known to serve as retention areas for algal growth and additionally serve as promoters of vertical mixing. Further, the negative gradients were consistent with lateral variations in properties such as $\mathrm{S}$ and ambient concentrations of limiting nutrients. Although lower bay tracks were adjacent to large western tributaries, there was no obvious coupling found between temporal variability in river flow and Chl. However, the larger tributaries would still influence $\mathrm{S}$ and nutrient distributions over longer time scales, particularly during the spring freshet. Along Track 1, inflow of shelf water at the bay's mouth and attendant dilution effects would accentuate the west to east pattern, producing the large lateral gradients that we observed using in situ data. The effects of western tributary inputs and estuarine circulation is progressively lower to the north, giving increasingly similar cross-bay conditions toward the mid-bay track. The relatively narrow boundaries of the mid-bay would also affect the consistent formation of lateral gradients in conservative and non-conservative properties, perhaps affecting the propensity of lateral gradients in this region.
There was no obvious effect of tidal phase on the lateral distribution of chl. However, at the onset of the 1990 spring bloom along Track 1 (see Fig. 4), oscillations in <chl> may have been due to tidal excursions of a phytoplankton patch. These flights were made at alternating flooding and ebbing stages (see Fig. 3), with the peaks in <chl> corresponding to the flooding tide stages. If a patch is tidally advected into and out of the track location, a pattern such as that seen in Fig. 4 would result. Similar effects were found in an aerial study over Nantucket Shoals, USA (Campbell \& Esaias 1985).

Spatial patterns of $\mathrm{chl}$ in the bay have also been found to be influenced by the absolute concentrations of DIN and DSi (Fisher et al. 1992). During the spring in the lower bay, DSi reaches concentrations that can limit diatom growth during the bloom season (Conley \& Malone 1992, Fisher et al 1992, Harding 1994, Glibert et al. 1995). Declines of DIN in this region also occur, and by summer, nitrogen limits phytoplankton growth in much of the lower bay (Fisher et al. 1992, Harding et al. 1994). Thus, the strong lateral gradient of DIN observed between the western and eastern stations not only identifies differences in water mass properties, but also shows concentrations that were near or below half-saturation constants for uptake and growth to the east and much higher to the west. Such strong gradients would be expected to elicit differences in phytoplankton abundance that would be expressed as lateral chl gradients. That is, the negative chl gradients consistently found in the lower bay tracks are associated with negative gradients in limiting nutrients.

It is clear that any description of spatial and temporal variations of chl in the bay, based on axial sampling alone, would be incomplete when such large variations can occur lateral to the mainstem, as Malone et al. (1986) found for the mesohaline. For instance, the strong lateral gradients of 4 - to 6 -fold that were observed on the ODAS tracks were comparable in magnitude to axial gradients along 100 to $150 \mathrm{~km}$ transects of the mainstem bay (Harding et al. 1986). These axial gradients have been linked to the interplay of light and nutrients and the seasonality of freshwater flow from the Susquehanna River (Harding et al. 1986, 1994, Fisher et al. 1988, 1992, Malone et al. 1988, Magnien 1990, Malone 1992, Harding 1994). Meteorological conditions in the estuarine watershed dictate flow from the river to the headwaters of the estuary, and in turn regulate phytoplankton dynamics in the system as a whole (Malone 1992, Harding 1994). It is suggested here that the hydrographical factors that control axial patterns of abundance also play a role in the lateral distributions that are found with the ODAS data. 
Chesapeake Bay exhibits significant small-scale patchiness relative to system-wide variability. Resolving this patchiness is vital to the understanding of how small-scale events influence the larger-scale patterns that are more commonly described. Clearly, sampling infrequently or with limited spatial coverage leads to poor recovery of information on small-scale or shortterm variations of surface chl. This is particularly problematic when it comes to observing episodes of high concentrations (i.e. blooms). This conclusion is similar to an earlier finding that shipboard sampling inadequately recovers information about high chl values such as occur in blooms, but does a reasonable job of estimating the mean value in the bay (Harding et al. 1994, 1995). The potential ramifications of undersampling high chl values include inadequate characterization of the bay-wide distribution of phytoplankton, particularly the timing, position and magnitude of blooms, and an absence of information on the effects of localized peaks and strong spatial gradients on secondary production. An accurate characterization of systemscale phytoplankton dynamics in the Chesapeake Bay requires a sampling strategy that not only involves sampling along the mainstem of the estuary, but also at locations lateral to the main north-south axis.

\section{Conclusion}

Lateral variability in chl was high along the 3 flight tracks examined in this study. Variability was highest during the spring bloom events of 1990 and was typically expressed as high west-low east gradients, particularly in the lower bay. There was no spring bloom in 1991, which resulted in low lateral variability throughout the bay. Bathymetry and estuarine circulation governed lateral differences in physical and chemical factors which are well known to influence the distribution of phytoplankton. Phytoplankton patch size in the lower bay was within the resolution of the soon-to-be-launched SeaWiFS sensor, which will provide even greater temporal coverage of the bay than that provided by aircraft.

Acknowledgements. We thank K Arrigo, E. Perry, F. Bub, H. Feng and $D$. Jacobs for their assistance in data analysis, $T$. Malone for critically reviewing the manuscript, and $C$. Moore, $R$. White and the CBP and LMER program coordinators for providing the in situ data. The contributions of S. Gennari and M. Mallonee are also gratefully acknowledged. Support for this study was provided by a Sea Grant Graduate Traineeship. Horn Point/Knapp Foundation Graduate Fellowship and a NASA/University of Maryland Summer Fellowship, and from funding of projects through Maryland Sea Grant on NOAA grants NA86AA-D-SG006, NA90AA-D-SG063, and NA16RGO362-01

\section{LITERATURE CITED}

Abbot MR (1993) Phytoplankton patchiness: ecological implications and observation methods. In: Levin SA, Powell TM, Steele JH (eds) Patch dynamics, lecture notes in biomathematics. Springer-Verlag, New York, p 37-48

Boicourt WC (1992) Influences of circulation processes on dissolved oxygen in the Chesapeake Bay. In: Smith DE, Leffler $M$, Mackleman $G$ (eds) Oxygen dynamics in the Chesapeake Bay. Maryland Sea Grant, College Park, MD, p $7-53$

Campbell JW (1995) The lognormal distribution as a model for bio-optical variability in the sea. $J$ Geophys Res 100(C7): $13237-13254$

Campbell JW, Esaias WE (1983) Basis for spectral curvature algorithms in remote sensing of chlorophyll. Appl Optics 22:1084-1093

Campbell JW, Esaias WE (1985) Spatial patterns in temperature and chlorophyll on Nantucket Shoals from airborne remote sensing data, May 7-9, 1981. J Mar Res 43:139-161

Cloern JE, Alpine AE, Cole BE, Wong RLJ, Arthur JF, Ball MD (1983) River discharge controls phytoplankton dynamics in the Northern San Francisco Bay Estuary. Estuar Coast Shelf Sci 16:415-429

Conley DJ, Malone TC (1992) Annual cycle of dissolved silicate in Chesapeake Bay: implications for the production and fate of phytoplankton biomass. Mar Ecol Prog Ser 81:121-128

Dustan P, Pinckney JL Jr (1989) Tidally induced estuarine phytoplankton patchiness. Limnol Oceanogr 34(2):410-419

Fisher TR, Harding LW Jr, Stanley DW, Ward LG (1988) Phytoplankton, nutrients, and turbidity in the Chesapeake, Delaware and Hudson estuaries. Estuar Coast Shelf Sci 27:61-93

Fisher TR, Peele ER, Ammerman JW, Harding LW Jr (1992) Nutrient limitation of phytoplankton in Chesapeake Bay Mar Ecol Prog Ser 82:51-63

Glibert PM, Conley DJ, Fisher TR, Harding LW Jr, Malone TC (1995) The spring bloom of 1990 in Chesapeake Bay. Mar Ecol Prog Ser 122:27-43

Harding LW Jr (1994) Long-term trends in the distribution of phytoplankton in Chesapeake Bay: roles of light, nutrients and streamflow. Mar Ecol Prog Ser 104:267-291

Harding LW Jr, Itsweire EC, Esaias WE (1992) Determination of phytoplankton chlorophyll concentrations in the Chesapeake Bay with aircraft remote sensing. Remote Sens Environ 40:79-100

Harding LW Jr, Itsweire EC, Esaias WE (1994) Estimates of phytoplankton biomass in the Chesapeake Bay from aircraft remote sensing of chlorophyll concentrations 1989-92. Remote Sens Environ 49:41-56

Harding LW Jr, Itsweire EC, Esaias WE (1995) Algorithm development for recovering chlorophyll concentrations in the Chesapeake Bay using aircraft remote sensing 1989-91. Photogramm Eng Remote Sens 61:177-185

Harding LW Jr, Meeson BW, Fisher TR (1986) Phytoplankton production in two East coast estuaries: photosynthesislight functions and patterns of carbon assimilation in Chesapeake and Delaware Bays. Estuar Coast Shelf Sci 23:773-806

Haury LR, McGowan JA, Wiebe PH (1978) Patterns and processes in the time-space scales of plankton distributions. In: Steele JH (ed) Spatial pattern in plankton communities. Plenum Press, New York, p 277-327

Heasly P, Pultz S, Batiuk R (1989) Chesapeake Bay basin monitoring program atlas, Vol 1 Water quality and other physiochemical monitoring programs. US Environmental Protection Agency, Annapolis, MD 
Itsweire EC, Phillips OM (1987) Physical processes that control circulation and mixing in estuarine systems. In: Lynch MP. Krome EC (eds) Perspectives on the Chesapeake Bay: recent advances in estuarne sciences. Chesapeake Research Consortium, Solomons, MA, Publ No 127:57-73

Mackas DL, Denman KL, Abbott MR (1985) Plankton patchiness: biology in the physical vernacular Bull Mar Sci $37(2): 652-674$

Magnien RE (1990) Spring phytoplankton bloom failure in Chesapeake Bay and impact upon hypoxia. EOS 71:185

Malone TC (1992) Effects of water column processes on dissolved oxygen: nutrients, phytoplankton and zooplankton. In: Smith D, Leffler M, Mackiernan G (eds) Oxygen dynamics in Chesapeake Bay: a synthesis of research. Maryland Sea Grant, College Park, MD, p 61-112

Malone TC. Crocker LH, Pike SE, Wendler BW (1988) Influences of river flow on the dynamics of phytoplankton production in a partially stratified estuary. Mar Ecol Prog Ser 48:235-249

Malone TC, Kemp WM, Ducklow HW, Boynton WR, Tuttle $\mathrm{JH}$, Jonas RB (1986) Lateral variation in the production and fate of phytoplankton in a partially stratified estuary. Mar Ecol Prog Ser 32:149-160

Marshall HG (1995) Autotrophic picoplankton distribution and abundance in the Chesapekeake Bay, USA. Marine Nature 4:33-42

Marshall HG, Alden RW (1991) Phytoplankton abundance, composition and trends within the lower Chesapeake Bay and three tributaries. In: Mihursky J, Chaney A leds) New perspectives in the Chesapeake System: a research and management partnership. Proc 2nd Chesapeake Bay Research Conference, Baltimore, Maryland, 4-6 Dec 1990, Chesapeake Research Consortium, Solomons, MD,

This article was presented by M. R. Lewis, Halifax,

Nova Scotia, Canada
Publ No. 137:517-522

Pritchard DW (1952) Salinuty distribution and circulation in the Chesapeake Bay estuarine system. J Mar Res 11: $106-123$

Powell TM, Cloern JE, Walters RA (1986) Phytoplankton spatial distribution in South San Francisco Bay: mesoscale and small-scale variability. In: Wolfe DA (ed) Estuarine variability. Academic Press, Orlando, FL, p 369-383

Sanford L.P, Sellner KG, Breitburg DL (1990) Covariability of dissolved oxygen with physical processes in the summertime Chesapeake Bay. J Mar Res 48:567-590

Selıger HH, McKinley KR, Biggley WH, Rıvkin RB, Aspden KRH (1981) Phytoplankton patchiness and frontal regions. Mar Biol 61:119-131

Steele JH (1974) Spatial heterogeneity and population stability. Nature 248:83

Tyler MA (1984) Dye tracing of a subsurface chlorophyll maximum of a red-tide dinoflagellate to surface frontal regions. Mar Biol 78:285-300

Tyler MA, Seliger HH (1978) Annual subsurface transport of a red tide dinoflagellate to its bloom area: water circulation patterns and organism distributions in the Chesapeake Bay. Limnol Oceanogr 23:227-246

van Es HM (1993) The spatial nature or soil variability and its implications for field studies. In: Levin SA, Powell TM, Steele JH (eds) Patch dynamics, lecture notes in biomathematics. Springer-Verlag. New York, p 27-36

Wiebe PH (1971) A computer model study of zooplankton patchiness and its effect on sampling error Limnol Oceanogr 15:205-217

Yoder JA, Aiken J, Swift RN, Hoge FE, Stegman PM (1993) Spatial variabllity in near-surface chlorophyll a fluorescence measured by the Airborne Oceanographic Lidar (AOL). Deep Sea Res 40:37-53

Manuscript first received: April 1, 1995

Revised version accepted: September 23, 1996 